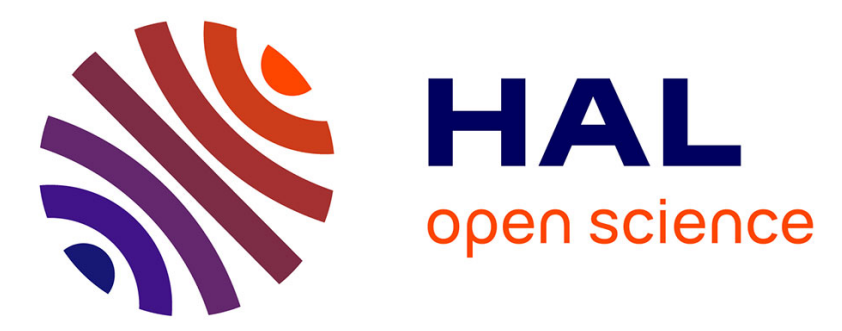

\title{
Increased permeability of blood vessels after reversible electroporation is facilitated by alterations in endothelial cell-to-cell junctions
}

Bostjan Markelc, Elisabeth Bellard, Gregor Sersa, Tanja Jesenko, Sandrine Pélofy, Justin Teissié, Robert Frangez, Marie-Pierre Rols, Maja Cemazar, Muriel Golzio

\section{To cite this version:}

Bostjan Markelc, Elisabeth Bellard, Gregor Sersa, Tanja Jesenko, Sandrine Pélofy, et al.. Increased permeability of blood vessels after reversible electroporation is facilitated by alterations in endothelial cell-to-cell junctions. Journal of Controlled Release, 2018, 276, pp.30-41. 10.1016/j.jconrel.2018.02.032 . hal-02390812

\section{HAL Id: hal-02390812 https://hal.science/hal-02390812}

Submitted on 19 Mar 2021

HAL is a multi-disciplinary open access archive for the deposit and dissemination of scientific research documents, whether they are published or not. The documents may come from teaching and research institutions in France or abroad, or from public or private research centers.
L'archive ouverte pluridisciplinaire HAL, est destinée au dépôt et à la diffusion de documents scientifiques de niveau recherche, publiés ou non, émanant des établissements d'enseignement et de recherche français ou étrangers, des laboratoires publics ou privés. 
Increased permeability of blood vessels after reversible electroporation is facilitated by alterations in endothelial cell-to-cell junctions

Bostjan Markelc, $\mathrm{PhD}^{\mathrm{a}, \mathrm{b}, *}$, Elisabeth Bellard, $\mathrm{PhD}^{\mathrm{a}, *}$, Gregor Sersa, $\mathrm{PhD}^{\mathrm{b}}$, Tanja Jesenko, $\mathrm{PhD}^{\mathrm{b}}$, Sandrine Pelofy, $\mathrm{PhD}^{\mathrm{a}}$, Justin Teissié, $\mathrm{PhD}^{\mathrm{a}}$, Robert Frangez, $\mathrm{PhD}^{\mathrm{c}}$, Marie-Pierre Rols, $\mathrm{PhD}^{\mathrm{a}}$, Maja Cemazar, $\mathrm{PhD}^{\mathrm{b}, \mathrm{d}, \dagger}$ and Muriel Golzio, $\mathrm{PhD}^{\mathrm{a}, \dagger}$

${ }^{a}$ Institut de Pharmacologie et de Biologie Structurale, Université de Toulouse, CNRS, UPS, BP 64182, 205 Route de Narbonne, F-31077, France

${ }^{b}$ Department of Experimental Oncology, Institute of Oncology Ljubljana, Zaloska 2, SI-1000 Ljubljana, Slovenia

${ }^{c}$ Institute of Preclinical Sciences, Veterinary Faculty, University of Ljubljana, Gerbiceva 60, SI-1000 Ljubljana, Slovenia

${ }^{\mathrm{d}}$ University of Primorska, Faculty of Health Sciences, Polje 42, SI-6310 Izola, Slovenia *these authors contributed equally to this work

\section{$\dagger$ Corresponding authors:}

1. Maja Cemazar: Department of Experimental Oncology, Institute of Oncology Ljubljana, Zaloska 2, SI-1000 Ljubljana, Slovenia; Telephone: +386(0)15879544, Fax: +38(0)15879434, E-mail: mcemazar@onko-i.si

2. Muriel Golzio: IPBS CNRS, UMR 5089, 205, Route de Narbonne, 31077 Toulouse Cedex, France; Telephone: +33(0)561175812, Fax: +33(0)561175994, E-mail: muriel.golzio@ ipbs.fr 


\begin{abstract}
Delivery of electric field pulses, i.e. electroporation (EP), to tissues has been shown to have a blood flow modifying effect. Indeed, the diameter of blood vessels exposed to EP is immediately reduced resulting in blood flow abrogation, followed by an increase in vascular permeability. The main cause of the increased permeability remains unknown. The aim of this study was to determine whether the in vivo effects of EP on permeability of blood vessels are linked to the permeabilization of endothelial cells' membrane (EC) and/or disruption of cell-to-cell junctions. We used a dorsal window chamber model in C57B1/6 mice coupled with multiphoton microscopy and fluorescently labelled antibodies against PECAM-1 (CD31) to visualize endothelial cell-to-cell junctions. Clinically validated EP parameters were used and behavior of cell-to-cell junctions, in combination with leakage of $70 \mathrm{kDa}$ fluorescein isothiocyanate labelled dextran (FD), was followed in time. After EP, a constriction of blood vessels was observed and correlated with the change in the shape of ECs. This was followed by an increase in permeability of blood vessels for $70 \mathrm{kDa} F D$ and a decrease in the volume of labelled cell-to-cell junctions. Both parameters returned to pretreatment values in $50 \%$ of mice. For the remaining 50\%, we hypothesize that disruption of cell-to-cell junctions after EP may trigger the platelet activation cascade. Our findings show for the first time in vivo that alterations in cell-to-cell junctions play an important role in the response of blood vessels to EP and explain their efficient permeabilization.
\end{abstract}

Keywords: Electroporation, electropermeabilization, vascular effects, endothelial cells, cell junctions, intravital microscopy 


\section{INTRODUCTION}

Tumor microenvironment plays a major role in tumor initiation and progression and therefore represents a potential target for tumor treatment. One of the first components of tumor microenvironment that became a topic of intensive research was tumor vasculature. Two types of vascular targeted therapies were developed: anti-angiogenic therapy, which aims to prevent the formation of new tumor vessels and vascular disrupting therapy, which targets existing tumor vasculature. Although the distinct mechanism of action between the two therapies is clear, some of the vascular targeting drugs or therapies, such as C9, deoxypodophyllotoxin, trans-3,5,4'-trimethoxystilbene, siRNA targeting endoglin and ENMD-1198 exert both antiangiogenic as well as vascular disrupting action [1-6].

In that context, one of the promising vascular disrupting therapies is electrochemotherapy (ECT). ECT combines the local application of electric pulses and the systemic or local injection of antitumor chemotherapeutic drugs such as bleomycin or cisplatin $[7,8]$. Electroporation/electropermeabilization (EP), i.e. application of well-defined electric pulses to cells or tissues, indeed induces the reversible permeabilization of cell membranes. The treatment results in a facilitated delivery into the cells of non-permeant or poorly permeant molecules [9,10]. Although ECT is nowadays already in routine clinical practice for treatment of subcutaneous tumors throughout Europe [11,12], mechanisms involved in antitumor effectiveness are still not fully understood. Reversible permeabilization of cell membrane resulting in enhanced cytotoxicity of chemotherapeutics into the cells is the basic mechanism of the antitumor effectiveness of electrochemotherapy [13,14]. In addition, it has been observed that EP alone induces blood modifying effects in tumors and normal tissues $[15,16]$, but when combined with chemotherapeutics it also results in disruption of tumor vasculature, without affecting adjacent normal vasculature [17]. This dual effect of ECT has clinical importance. On one hand, due to the vascular disrupting action of ECT, it has proven to be successful in the treatment of bleeding tumors $[18,19]$. On the other hand, it can be safely applied to tumors that lie in the vicinity of big normal blood vessels, as was recently demonstrated in a clinical study on liver metastases of colorectal cancer [20]. Moreover, even when used close to the heart, electroporation proved to be a safe method [21-23].

Recently, the effects of EP on normal skin blood vessels were thoroughly investigated by direct visualization. Namely, with the use of intravital microscopy using fluorescence stereomicroscope in a mouse dorsal window chamber (DWC) model we demonstrated that the application of electric pulses with different parameters leads to a rapid increase in skin blood vessel permeability. Additionally, the application of electric pulses induced an immediate constriction of blood vessels, which although transient produced a reduction in the perfusion of the exposed vessels, the so-called vascular lock that lasted a maximum of 10 min [24]. Furthermore, a histological analysis of the treated skin revealed extravasation of erythrocytes and infiltration of leukocytes together with some reversible damage to the skin [25]. Furthermore, using mathematical modelling based on the data of extravasation of fluorescently labelled dextrans, we showed a higher microvascular permeability after EP for smaller molecules $(70 \mathrm{kDa})$ compared to the larger ones $(2000 \mathrm{kDa})$ [26]. These data provided further evidence confirming the previously proposed model of the underlying 
mechanisms of blood flow modifying effects of EP in normal tissues [27]. However, whether the significant increase in permeability of blood vessels observed in vivo is due to the loss of contractility of endothelial cells (EC) and disruption of endothelial cell-to-cell junctions observed in vitro (paracellular transport) [28] or to the overall increase of cell membrane permeability (transcellular transport), remains to be demonstrated.

Therefore, to determine whether the in vivo effects of EP on permeability of blood vessels are linked to the permeabilization of ECs membranes and/or disruption of cell-to-cell junctions, an in vivo analysis at a cellular resolution was performed in DWC model in mice using intravital fluorescence multiphoton microscopy (IVMM). Intravital microscopy (IVM) has played a key role in studies of the morphology and function of blood vessels and their response to different treatments. Imaging techniques and offline analysis methods are a vital and active area of biological research [29]. The high resolution and deep tissue penetration of multiphoton microscopy (IVMM) have made this technique currently the best choice for intravital studies of biological events at a cellular resolution. Furthermore, the dependency of the fluorescence lifetime of a fluorophore on its molecular environment but not on its concentration has enabled the researchers to get deep inside the interactions of a fluorophore with its biological environment with Fluorescence Lifetime Imaging (FLIM) [30].

In this study, we aim to study the temporal and spatial changes in the permeability of cell membranes and the integrity of endothelial cell-to-cell junctions after EP. To achieve this, we applied electric pulses either to murine endothelial cells in vitro or directly to the normal skin in mice. We used fluorescently labelled antibodies (Alexa Fluor) targeting CD31 (PECAM-1) or VE-Cadherin, molecules in endothelial cell-to-cell junctions, $70 \mathrm{kDa}$ fluorescein isothiocyanate (FITC) labeled dextran (FD) and followed the resulting changes in vitro and by using IVMM and FLIM.

\section{MATERIALS AND METHODS}

\subsection{Reagents}

Fluorescein isothiocyanate (FITC) labeled dextran (FD) $(70 \mathrm{kDa})$ was purchased from Sigma Aldrich (St. Louis, MO, US). It was dissolved in phosphate-buffered saline (PBS) and washed through $30 \mathrm{kDa}$ spin filter (Sartorius Stedim Biotech $\mathrm{GmbH}$, Goettingen, Germany) at $3000 \mathrm{rpm}$ to remove any free FITC or low molecular weight contaminants. The high molecular weight component was resuspended in PBS and used in mice at $37.5 \mathrm{mg} / \mathrm{ml}(3.75$ $\mathrm{mg} /$ mouse in $100 \mu \mathrm{l}$ ) concentration. The CD31 (PECAM-1) rat anti-mouse antibody (clone 390, unconjugated; Life Technologies) was custom conjugated to Alexa Fluor ${ }^{\circledR} 555$ or Alexa Fluor $^{\circledR} 647$ by Life Technologies. Hoechst 33342 nuclear dye was purchased from Life Technologies.

\subsection{Mice}

Adult female C57B1/6 mice (Charles River Laboratories, France) weighing between 18$23 \mathrm{~g}$ were used as hosts for dorsal window chamber (DWC) surgery. All animal experiments were conducted in accordance with French procedural guidelines for animal handling and with approval from the Regional Ethical Review Committee (MP/02/36/10/10). 


\subsection{Dorsal window chamber $(D W C)$ surgery}

Surgery was carried out as previously described [17,24,25] under general anesthesia using intraperitoneal injection of Ketamine ( $4 \mathrm{mg} / \mathrm{kg}$, MERIAL, Lyon, France) and Xylazine (20 $\mathrm{mg} / \mathrm{kg}$, Bayer, Puteaux, France). Briefly, animals were kept warm using heating pads and an aseptic technique was used throughout the surgical procedure. Two symmetrical titanium frames (APJ Trading Co., Ventura, CA, US) sandwiched an extended double layer of dorsal skin which was attached to them with stainless steel screws and sutures. After the implantation of the frames, one layer of skin ( 12-mm diameter) was surgically removed to create an observation window. Then, all the underlying fat and connective tissue that was not associated with the remaining layer of the skin was carefully dissected away with microsurgical tools. Then, sterile PBS was added into the created hole and a sterile glass coverslip was attached to the open frame with a stainless steel clip to cover the surgical site and provide visual access to the vascular network of the skin. After the surgery and on the following day, Profenid (Sanofi-Aventis, Paris, France) was injected, intramuscularly, to provide analgesia and to avoid inflammation $(10 \mathrm{mg} / \mathrm{kg}, 50 \mu \mathrm{l}$ in each thigh).

\subsection{In vivo electropermeabilization}

EP was carried out 3 to 7 days following the surgery, by application of standard ECT pulse parameters [11]: 8 square wave electric pulses, amplitude per distance $1300 \mathrm{~V} / \mathrm{cm}$, pulse length $100 \mu \mathrm{s}$, repetition frequency $1 \mathrm{~Hz}$, generated by an electropulsator (Cliniporator ${ }^{\mathrm{TM}}$, IGEA s.r.l., Carpi, Italy). Pulses were delivered by two parallel stainless steel rods (length $5 \mathrm{~mm}$, width $1.3 \mathrm{~mm}$ ) $4 \mathrm{~mm}$ apart, which were placed in contact with the intact skin on the opposite side of the cover glass. Good contact was assured by means of a conductive gel (Eko-gel, Egna, Italy). Mice in which no EP was applied were regarded as a control group. To visualize the cell-to-cell junctions in vivo the fluorescently labelled CD31 rat anti-mouse antibody (PECAM-1) was injected intravenously $(25 \mu \mathrm{g}$ in $100 \mu \mathrm{l}) 4-6 \mathrm{~h}$ before IVMM and FD $(3.75 \mathrm{mg}$ in $100 \mu \mathrm{l}) 3-5 \mathrm{~min}$ before IVMM to observe its extravasation from blood vessels into the tissue after EP. To visualize the change in the shape of endothelial cell nuclei, a $150 \mu \mathrm{l}$ of PBS containing $1 \mathrm{mg} / \mathrm{mL}$ Hoechst was injected in the retro-orbital plexus 1 min before IVMM. There was no temperature control inside the DWC during the experiments.

\subsection{Intravital multiphoton microscopy}

Intravital multiphoton microscopy (IVMM) was carried out using a 7MP upright fluorescence microscope (Carl Zeiss S.A.S., Jena, Germany), equipped with a 20x objective (NA 0.95) and coupled to a Ti-Sapphire femtosecond laser, Chameleon Ultra 2 (Coherent Inc) tuned to $720 \mathrm{~nm}$ or $820 \mathrm{~nm}$ in case of Alexa Fluor ${ }^{\circledR}$ 647, to simultaneously excite FITC and Alexa Fluor ${ }^{\circledR}$ 555. Throughout the experiment, animals were anaesthetized with inhalation anaesthesia (Vetflurane) and immobilized on a customized heated stage. Emitted light from labelled vessels (FITC dextran) and from endothelial cell-to-cell junctions (Alexa Fluor $^{\circledR} 555$ or Alexa Fluor ${ }^{\circledR} 647$ - PECAM-1) was detected through 500-550 nm and 565-610 $\mathrm{nm}$ or $640-710 \mathrm{~nm}$ bandpass filters with non-descanned detectors. Five min after an $i . v$. injection of $100 \mu \mathrm{l}$ of FD and before EP, a 3D image stack (x, y, z) of $101 \mathrm{x}-\mathrm{y}$ sections at a 
resolution of $1024 \times 1024$ and with z-spacing of $2 \mu \mathrm{m}$ was acquired and formed by averaging 2 video frames. Immediately after EP, this volume collection was repeated every 7 minutes during $90 \mathrm{~min}$ (7 times points) to create a 4D data sets. When mice were injected with Hoechst (emission filters) the signal was detected through a $485 \mathrm{~nm}$ shortpass emission filter. The acquired 4D data sets were stored and then analyzed off-line with Imaris software (Bitplane AG).

Platelets intravital microscopy was performed using an upright "Macrofluo" fluorescence macroscope (Leica Microsystems SA, Rueil-Malmaison, France), equipped with a Cool Snap HQ2 Camera (Roper Scientific, Photometrics, Tucson, AZ, USA). Animals were anaesthetized with inhalation anaesthesia (Vetflurane, Virbac France) throughout the experiment. Platelets and vessels were imaged by fluorescence using appropriate filters (excitation filter, BP: 480/40 and 560/40 nm, emission filter, BP 527/30 and 630/75 nm respectively). After injection of $100 \mu \mathrm{l}$ of Rhodamin Dextran $70 \mathrm{kDa}$, one image for each channel was acquired before EP and a stack of images was acquired immediately after. Images were taken every one minute for $10 \mathrm{~min}$ with an image acquisition software (Metavue, Metamorph, Molecular devices, Sunnyvale, CA, USA). The files were stored and analyzed off-line with an analysis software (ImageJ, National Institute of Mental Health, Bethesda, MD, USA).

\subsection{Intravital fluorescence lifetime imaging microscopy}

Intravital FLIM was carried out using multidimensional time-correlated single-photon counting (TCSPC) system based on SPC150 module (Becker Hickl, Germany) in combination with multiphoton laser scanning. For FLIM experiments, the laser was tuned to $820 \mathrm{~nm}$ to excite Alexa Fluor ${ }^{\circledR} 647$ and emitted photons from endothelial cell-to-cell junctions were detected through a 665-715 nm bandpass filter, on a high speed hybrid detector (HPM-100-40). A $36 \mu \mathrm{m}$ TCSPC-FLIM image stack (x, y, z) of 7 sections at a resolution of 256x256 and with z-spacing of $6 \mu \mathrm{m}$ was acquired and formed by averaging 16 video frames. For each $\mathrm{x}-\mathrm{y}$ section, the long acquisition time induced by the averaging (113s/section) allowed to collect enough photons to deliver an image with a representative decay curve in each pixel. The FLIM sections were analyzed with the SPCImage FLIM data analysis software (Becker \& Hickl, Germany).

\subsection{In vitro studies: Cell culture, electropermeabilization and immunofluorescence}

Immortalized mouse brain endothelial cell line bEnd.3 cells (ATTC, Manassas, VA, US) were grown to a confluent monolayer in Dulbecco's Modified Eagle's Medium (DMEM, Life Technologies) supplemented with $5 \%$ fetal bovine serum (FBS), $100 \mathrm{U} / \mathrm{mL}$ penicillin/streptomycin (Gibco-Invitrogen) in 8 well Nunc ${ }^{\mathrm{TM}}$ Lab-Tek $^{\mathrm{TM}}$ II Chamber Slide ${ }^{\mathrm{TM}}$ (Thermo Scientific, Waltham, MA, US) pre-coated with $0.1 \mathrm{mg} / \mathrm{ml}$ Matrigel $^{\mathrm{TM}}$.

To permeabilize the bEnd.3 cell monolayer in vitro, cells were first washed with EP buffer $\left(10 \mathrm{mM} \mathrm{K}_{2} \mathrm{HPO}_{4} / \mathrm{KH}_{2} \mathrm{PO}_{4}\right.$ buffer, $1 \mathrm{mM} \mathrm{MgCl}_{2}, 250 \mathrm{mM}$ sucrose, $\left.\mathrm{pH} 7.4\right)$ and then incubated in it during EP, which was performed with the following pulse parameters: 8 square wave electric pulses, amplitude per distance $600 \mathrm{~V} / \mathrm{cm}$, pulse length $100 \mu$ s, repetition frequency $1 \mathrm{~Hz}$. Pulses were generated by Electrocell S20 electropulsator (Betatech, St 
Orens, France) and delivered by plate electrodes with a distance of $7.3 \mathrm{~mm}$ between them. Cells were then incubated for $5 \mathrm{~min}$ in EP buffer (except in the group $0 \mathrm{~min}$, where the cells were fixed immediately after EP) before it was changed for DMEM.

To observe changes in cell-to-cell junctions, bEnd.3 cells were fixed in periodate-lysineparaformaldehyde buffer (PLP) for 15 minutes at room temperature, before or at $0,5,10,20$, 30 and 60 minutes after EP. To enable the visualization of junctions, bEnd.3 cells were successively incubated with Alexa Fluor ${ }^{\circledR} 555$ labelled rat anti-mouse CD31 antibody (2 $\mu \mathrm{g} /$ well) and Alexa Fluor ${ }^{\circledR} 647$ labelled rat anti-mouse VE-cadherin antibody $(0.5 \mu \mathrm{g} /$ well $)$. In-between labelling steps, the cells were washed $3 \mathrm{x}$ with PBS for $5 \mathrm{~min}$. Cell nuclei were stained with Hoechst 33342 dye (ThermoFisher). After labelling, the slides were mounted with ProLong® Gold Antifade Mountant, air dried for $24 \mathrm{~h}$ and the edges of cover glass were sealed with nail varnish.

Fixed bEnd.3 cells were observed with a FV1000 confocal microscope (Olympus) equipped with a 40x objective (NA 0.95). Alexa Fluor ${ }^{\circledR} 555$ and 647 were excited using 559 $\mathrm{nm}$ and $635 \mathrm{~nm}$ excitation lasers respectively, and detected through suitable filters $(570 / 55 \mathrm{~nm}$ and 705/100nm respectively) with PMT detectors. To image Hoechst a $405 \mathrm{~nm}$ laser diode was used and emitted light was detected through suitable bandpass filters (425/50nm). Different channels were acquired sequentially to prevent bleed through of dyes into other channels. Images were stored and analyzed off-line with ImageJ (NIH, Bethesda, US) image analysis software.

To quantify the VE-cadherin intensity in junctions in vitro a line profile (10 pixel width) was drawn in ImageJ across separate junctions and the maximum intensity within the junction was recorded for each time point after EP. Then, the mean maximum intensity within the junctions was normalized to the mean maximum intensity within the junction of the control non-treated cells.

\subsection{In vivo data analysis}

To determine the quantity of Alexa Fluor ${ }^{\circledR} 555$ labeled antibody and the quantity of FD in the intravascular and extravascular space in vivo the Imaris software was used. 3D volumes of interest were selected inside and outside the blood vessel and the mean fluorescence intensity in these volumes was measured for each channel separately (Alexa Fluor ${ }^{\circledR} 555$ and FD) and recorded for each time point (Fig. 1). Changes in fluorescence intensity were calculated as a percentage of variation compared to the image before EP, to avoid the variability between mice due to the different initial value of "before EP" mean fluorescence intensity. 


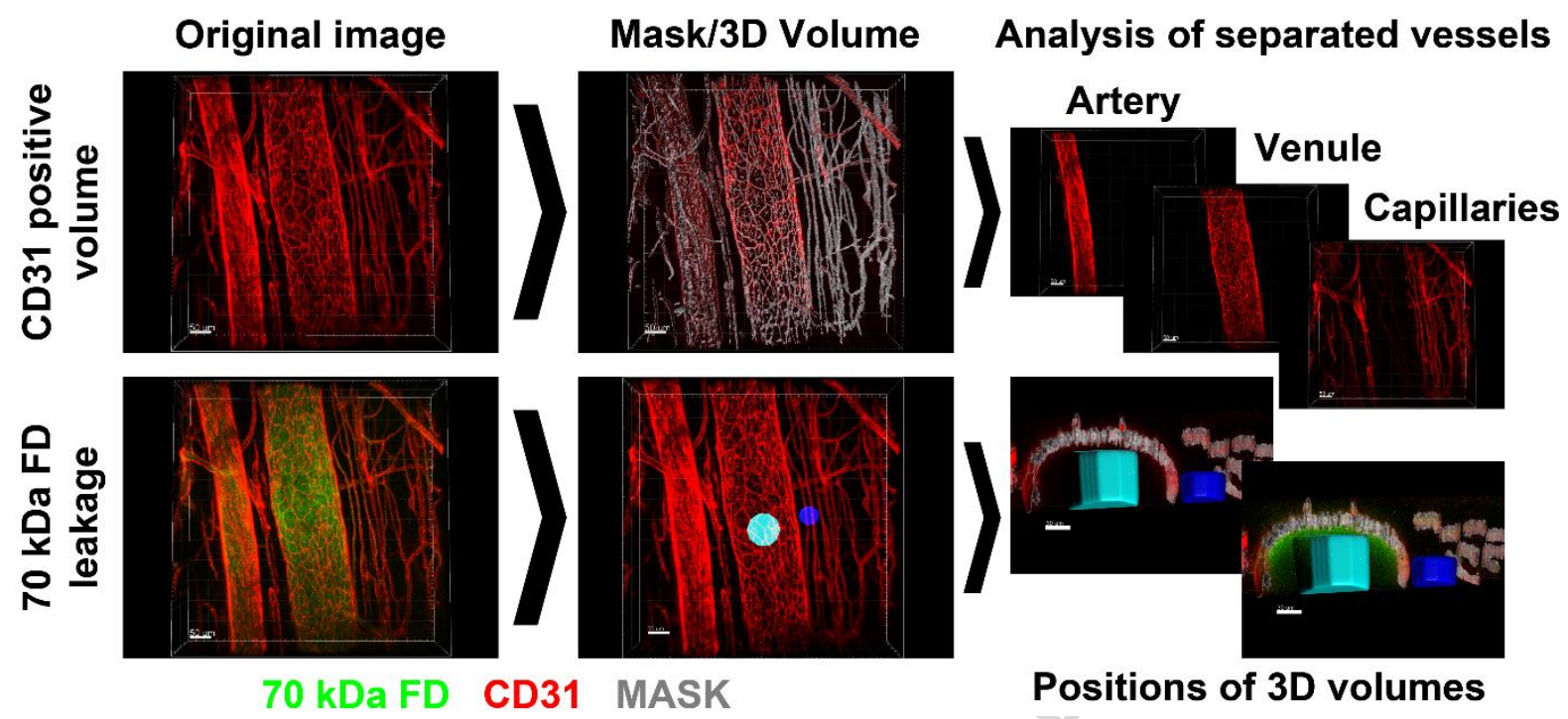

Fig. 1. Workflow of data analysis. To determine the volume of CD31 labelled junctions the "isosurface" module of Imaris (Bitplane) software was used. The isosurface masks were obtained for the entire vasculature as well as separately for artery, venule and capillaries (top panel). The quantification of FD leakage from blood vessels after EP was performed by positioning 2 separate $3 D$ volumes in the acquired $3 D$ image. One 3D volume (cyan) was placed inside a venule and the other (blue) was placed into the adjacent tissue where no blood vessels were present (bottom panel). Scale bars on all images are $50 \mu \mathrm{m}$, except in the 2 bottom right images where Scale bars are $30 \mu \mathrm{m}$.

To determine the changes in the quantity of CD31 labelling in the cell-to-cell junctions between endothelial cells in vivo, a mask of the Alexa Fluor ${ }^{\circledR} 555$ labelling was constructed with the Imaris "isosurface" module for each time point. On the initial 3D image acquired before EP the parameters for the construction of the isosurface mask were determined and were then applied on all subsequent images in the time series (Fig. 1). In order to differentiate the behavior of venules, arteries and capillaries after EP, a 3D crop of the venule and the artery was performed and separate channels were created for each one. Then, these 2 channels were subtracted from the original image to give a third channel comprised from the remaining capillaries (Fig. 1). On these newly formed channels the isosurface masks were created with the same parameters as used for the creation of the original isosurface mask of the entire vasculature. The volumes of these masks were then recorded for each time point and normalized to the volume of the isosurface mask constructed on the first acquired image in the control group or to the image acquired before EP for each mouse separately. Then, for each time point the mean value of these volumes was calculated. Additionally, to counteract the effect of photo bleaching due to repetitive imaging of the same area of interest, the values were further normalized to the mean value of the control group for each time point separately. After calculating the volumes of CD31 labelled junctions the mice in EP group were divided into two subgroups. The first group consisted of mice where a return of volume of CD31 labelled junctions was observed after an initial decrease (Return) and the second group consisted of mice where there was no return of volume of CD31 labelled junctions during the entire observation period (No return). 
To determine the change in the length and the width of endothelial cells, their length (longest line horizontal to the length of the vessel) and their width (longest line perpendicular to the length) was measured in 3D in Imaris (Bitplane) for individual endothelial cells. The change in the measured value was then calculated as the $\%$ of change from the obtained measurement on the first acquired image.

The Alexa Fluor ${ }^{\circledR} 647$ fluorescence lifetime in the CD31 labelled junctions was calculated as follows. Briefly, the $\mathrm{Z}$ slice with the cells junctions was selected and a region of interest was defined surrounding the venule. On a bright position (representative of CD31 labelled cell-tocell junctions), the "shift" value was changed to improve the $\chi^{2}$. Then, with the "calculate decay matrix" option of the SPCImage FLIM software (Becker\&Hickl), the decay curve in the individual pixels of the region of interest was fitted with an appropriate decay model function, i.e., a single-exponential model, resulting in a single fluorescence lifetime per pixel. Finally, the mean lifetime values of Alexa Fluor ${ }^{\circledR} 647$ fluorescence was calculated from all the pixels of the region of interest.

To determine vessels leakage according to platelets aggregation, increase in fluorescence intensity outside the blood vessels was determined in regions of interest manually drawn face to vessels positive or negative in platelets (ImageJ, National Institute of Mental Health, Bethesda, MD, USA). The percentage of variations was calculated to avoid the variability between mice in the initial value of tissue fluorescence intensity.

\subsection{Statistical analysis}

Statistical analysis was carried out using Prism 5 Statistical software (GraphPad Software Inc., San Diego, CA). For comparison of control and EP groups, Student t-tests were used, and for multiple comparisons, a one-way ANOVA with Dunnett's post-test. A value of $\mathrm{p}<$ 0.05 was considered to represent a significant difference between groups.

\section{RESULTS}

3.1 3D Multiphoton microscopy revealed the changes in blood vessels diameter and their increased permeability after EP

Our previous studies showed that EP increases the extravasation of macromolecules from blood vessels into surrounding tissue [24,25]. In order to confirm this observation and to define it in 3D space, we used fluorescently labelled antibody against CD31 to visualize the endothelial cell-to-cell junctions, which enabled us to see the blood vessels wall and measure the vessels' diameter (Fig. 2A, B, Fig. 3A, B). Additionally, we intravenously injected 70 $\mathrm{kDa} \mathrm{FD}$ before $\mathrm{EP}$ and then determined its extravasation by the relative variation of mean fluorescence intensity (green channel) outside the blood vessels (Fig. 2A, B). 


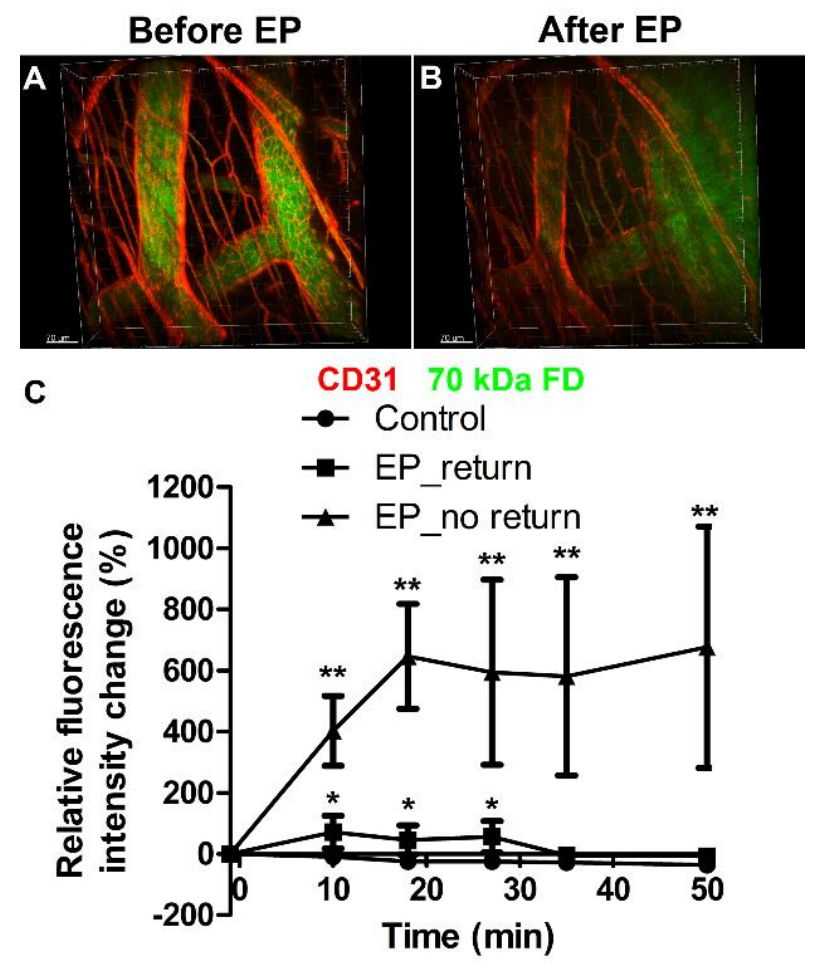

Fig. 2. Direct visualization and quantification of FD leakage kinetics after EP. Visualization of the increase of the permeability of blood vessels (CD31 labelled junctions in red) for $70 \mathrm{kDa} F D$ (green) after EP (A, B). Eight square wave electric pulses, amplitude per distance $1300 \mathrm{~V} / \mathrm{cm}$, pulse length $100 \mu \mathrm{s}$, repetition frequency $1 \mathrm{~Hz}$, were applied in EP groups. $70 \mathrm{kDa} F D$ was i.v injected 3 min before the first image. Relative variation of mean fluorescence intensity as a function of time for $70 \mathrm{kDa} F D$ after EP in the tissue outside blood vessels $(C)$ in Control mice $(n=10, \bullet)$ in comparison with groups where EP was applied. $\mathbf{a}$ : group with a return of CD31 labelled junctions (EP_return, $n=6)$ and $\mathbf{\Lambda}$ : group with no return of CD31 labelled junctions (EP_no return, $n=6)$. Mean values $\pm S E M$ are shown in $C$. * $-P<0.05$ compared to control. $* *-P<0.05$ compared to control and EP return group. Scale bars: $70 \mu \mathrm{m}$.

Immediately after EP, the diameter of blood vessels was reduced (Fig. 3B). This change was transient and the diameter of blood vessels returned to pre-EP value already on the second acquired image ( 14 min after EP, Supp Fig. 1). Moreover, the decrease of the diameter was also accompanied by the change of the shape of $\mathrm{EC}$, both in venules and arteries (Fig. 3C-G). The individual EC in venules were clearly visible, as the CD31 antibody labelled the cell-to-cell junctions between neighboring cells. This enabled to determine the size and the shape of individual cells and follow their changes at the single cell level after EP (Fig. 3C, D). The application of electric pulses reduced the length as well as the width of individual EC's on venules and altered their shape (Fig. 3E, G). Moreover, it also permeabilized some EC's as indicated by uptake of propidium iodide after EP (Supp Fig 2). EC's in arteries could not be as easily distinguished, especially after EP, where the large reduction in diameter after EP did not allow to identify single cells (Fig. 3F). Also, the labeling of cell-to-cell junctions was different than in venules, providing a more tile like appearance of EC's in arteries (Fig. 3A, F). Therefore, Hoechst was intravenously injected to label the nuclei and enable the determination of changes in shape on a single cell/nuclei level in arteries (Fig. 3F). This revealed that after EP there was a decrease in size of EC as well as 
their nuclei in arteries as was the case in venules (Fig. 3F, G, Supp Movie 1). However, due to the described difficulties, it was not possible to follow the same individual cells in arteries before and after EP.
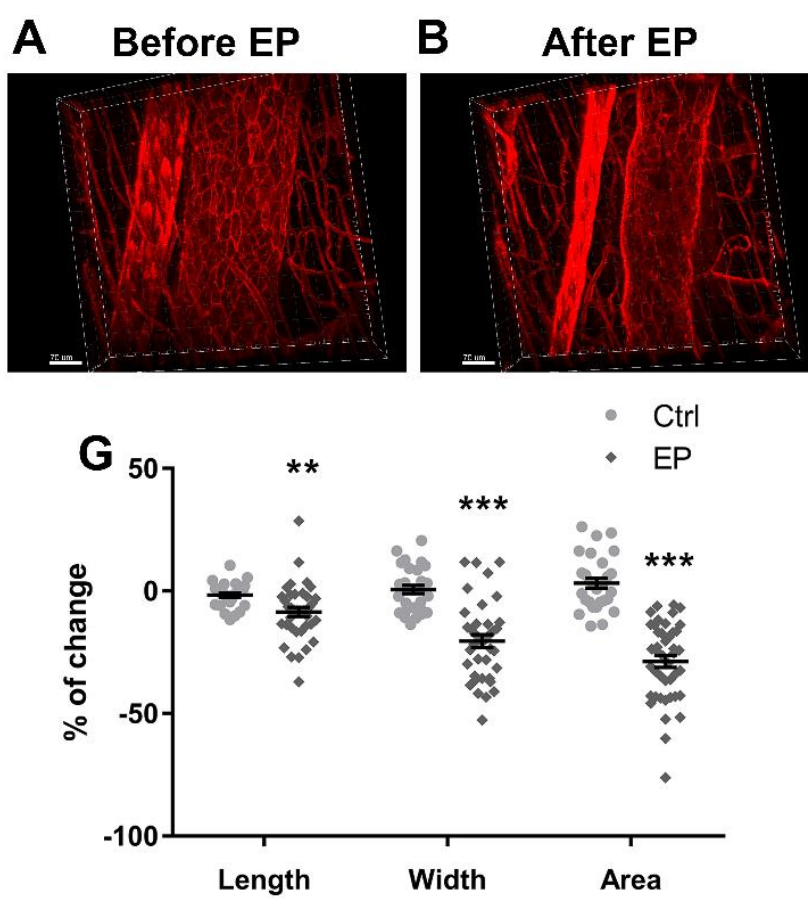
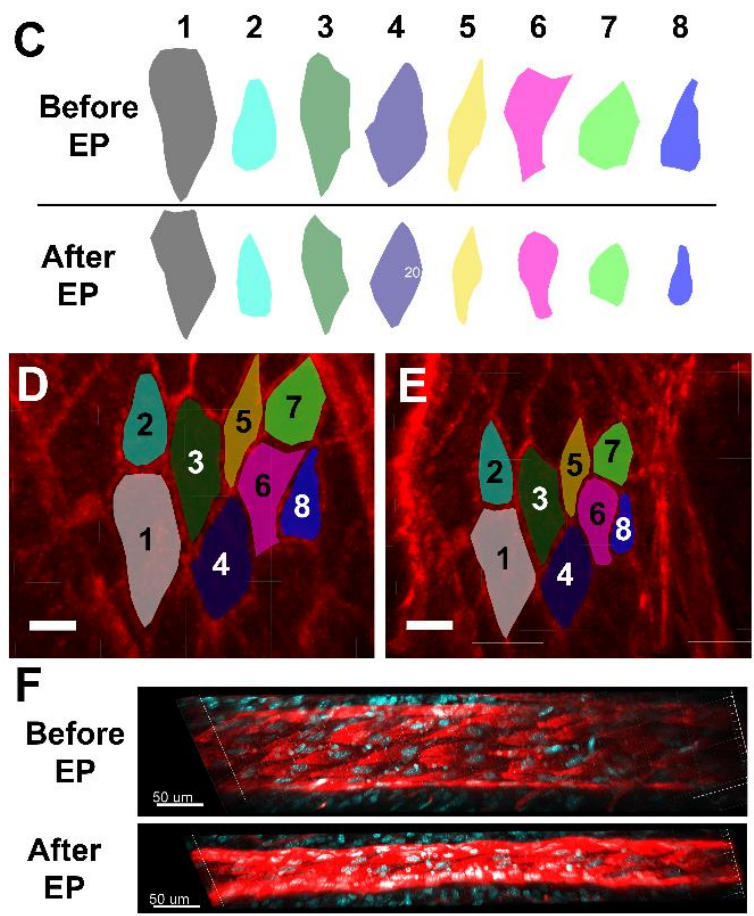

Fig. 3. Reduction in diameter of blood vessels and change in shape of EC after EP. The reduction of diameter of artery (left large vessel) and venule (right large vessel) after EP (A, B). Eight square wave electric pulses, amplitude per distance $1300 \mathrm{~V} / \mathrm{cm}$, pulse length $100 \mu \mathrm{s}$, repetition frequency $1 \mathrm{~Hz}$, were applied. Scale bar: 70 $\mu m$. Change of the shape of individual EC in venules after EP (E). Individual EC in C, delineated by CD31 staining, marked with a different color and then the same cells traced in D after EP and their shape marked again. Scale bars: 20 um. Change of cell size (CD31 staining in red) and nuclei size (Hoechst in cyan injected i.v. 1 min before first image) in arteries due to EP(F). Scale bars: $50 \mu \mathrm{m}$. Quantification of the \% of change in the length and width of individual endothelial cells after EP, or between the first and the second image in case of the control group (Ctrl) (G). Data presented as mean \pm SEM. $n>25$ cells/condition from $n>5$ mice per condition. ** $P<0.01$, *** $P<0.001$ vs Ctrl.

The changes in diameter of blood vessels were accompanied by a concomitant increase in permeability. After EP we observed a high and statistically significant increase in relative variation of mean fluorescence intensity for $70 \mathrm{kDa} F D$ in the tissue outside the blood vessels (Fig. 2C, Supp Movie 2). The highest increase in relative variation of mean fluorescence intensity in the tissue was obtained on the second image after EP (i.e. $7 \mathrm{~min}$ ) and then reached a plateau value $17 \mathrm{~min}$ after EP (Fig. 2C). In contrast, the relative variation of mean fluorescence intensity after EP inside the blood vessels was decreasing at the similar rate as in the Control group, indicating that the EP induced leakage did not substantially reduce the pool of circulating FD (Supp Fig. 3). There was a significant difference in the amount of FD leakage between the group of mice where there was no return of CD31 labelling after EP and the group where CD31 labelling returned after EP (Fig. 2C). 


\subsection{In vivo effects of EP on endothelial cell-to-cell junctions}

In order to determine if the increased permeability of blood vessels for macromolecules could be explained by the changes in the cell-to-cell junctions, as already shown by in vitro data on human umbilical vein EC [28], we used the same approach as before, labeling of EC cell-to-cell junctions with fluorescently labelled antibody against CD31. The intensity of the labelling of CD31 in the junctions, correlating to the amount of CD31 present in them, was then compared at different time points before and after EP and to the untreated control group to give a measure of the changes in the quantity of CD31 present in the junctions. The loss of CD31 labelling from the cell-to-cell junctions induced by EP is illustrated in Figure 4 (Fig. 4A, Supp Movie 3) and was associated with a rapid extravasation of $70 \mathrm{kDa} F D$ from the exposed venules (Fig. 2, Fig. 4).
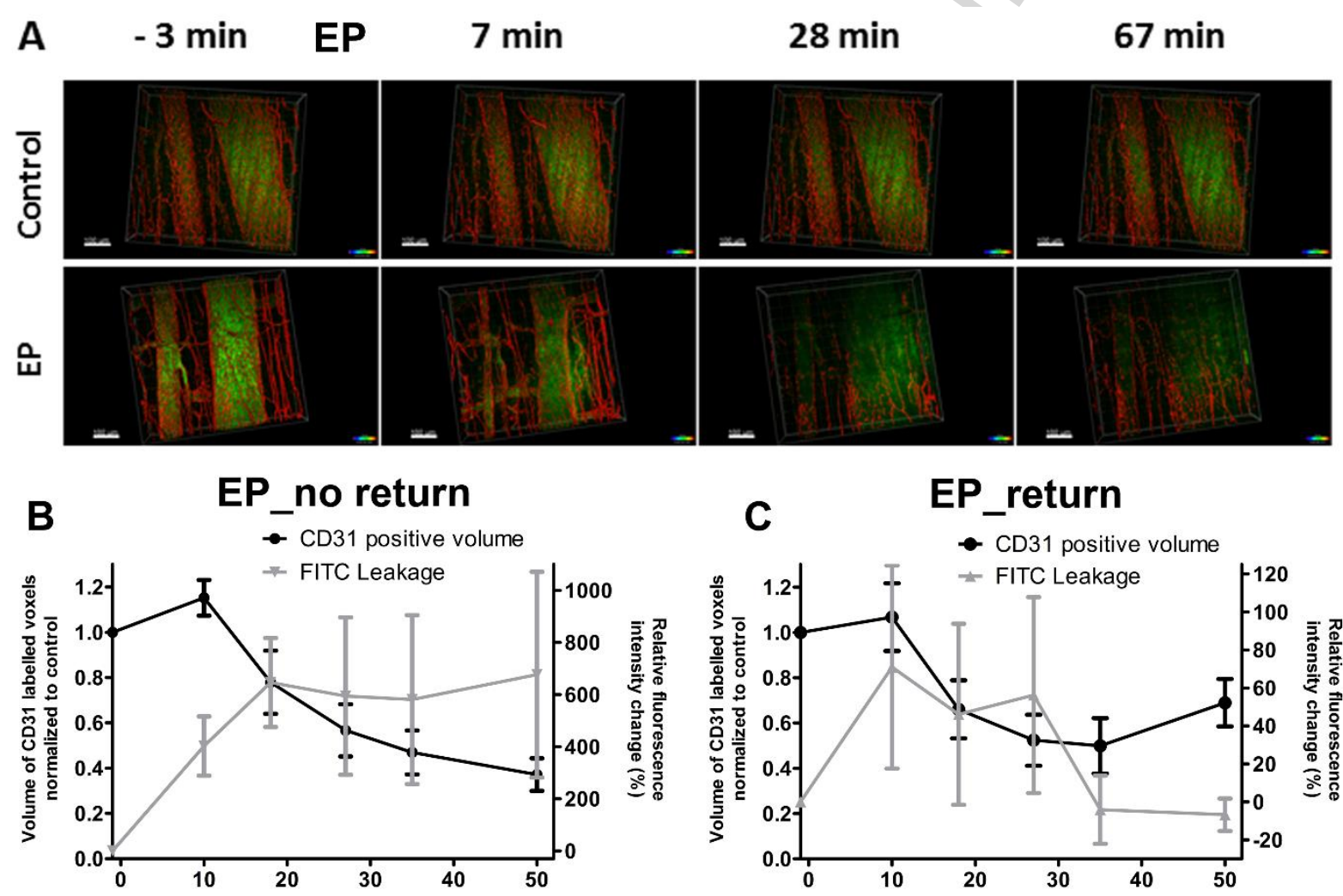

Fig. 4. Changes in the volume of CD31 labelled cell-to-cell junctions in relation to 70 kDa FD leakage. Representative images of the changes in the determined volume of CD31 labelled cell-to-cell junctions in Control group and in the group where EP was applied (A). Eight square wave electric pulses, amplitude per distance $1300 \mathrm{~V} / \mathrm{cm}$, pulse length $100 \mu \mathrm{s}$, repetition frequency $1 \mathrm{~Hz}$, were applied in EP groups. $70 \mathrm{kDa} F \mathrm{was}$ injected i.v $3 \mathrm{~min}$ before the first image. Scale bar: $100 \mu \mathrm{m}$. The volume of CD31 labelled cell-to-cell junctions normalized to control $(n=10)$ in relation to time (left y axis) was plotted together with relative mean fluorescence intensity changes for $70 \mathrm{kDa} F D$ (right y axis) to show time relation between them $(B, C)$. In $(B)$ the group of mice where there was no return of CD31 positive volume after EP is shown $(n=6)$ and in $(C)$ the group of mice where there was return of labeling after EP $(n=6)$ is shown. Error bars indicate SEM.

The time course of cell-to-cell junctions' changes was measured by the relative variation of the volume of CD31 labelled voxels in the acquired 3D images of blood vessels (Fig. 4B, C). A gradual and significant decrease in the volume of CD31 labelled voxels was 
obtained after EP with a return to the control levels in 8 out of 15 mice, which corresponded to a decrease of relative variation of fluorescence intensity of $70 \mathrm{kDa} F D$ (Fig. 4C). In contrast, the volume of CD31 labelled voxels in the remaining 7 mice continued to decrease throughout the observation period (Fig. 4B). A small linear decrease of $\sim 8 \%$ per image was also observed in the control group due to Alexa Fluor ${ }^{\circledR} 555$ photo bleaching, however, this decrease was significantly lower compared to what was observed with EP group (Supp Fig. 4, Supp Movie 4).

These results could demonstrate that the initial significant alterations in endothelial cell-to-cell junctions correlated with an increased leakage of $70 \mathrm{kDa} F D$ from blood vessels into the tissue and a partial restoration of these junctions in some vessels. This was confirmed by direct comparison of the timeline of relative variation of mean fluorescence intensity for $70 \mathrm{kDa} F D$ and the changes in the volume of CD31 labeled junctions (Fig. 4B, C), where it was clearly demonstrated that the largest changes in relative variation of mean fluorescence intensity are achieved simultaneously with the largest decrease in the volume of CD31 labelled junctions (Fig. 4B). In the group where the cell-to-cell junctions labelling did not return, the relative variation of mean fluorescence intensity reached a plateau level $\sim 20 \mathrm{~min}$ after EP, however it did not return to pretreatment levels, demonstrating that the permeability of blood vessel wall for $70 \mathrm{kDa} F D$ was still slightly increased (Fig. 4B). In contrast, in the group where the return of cell-to-cell junctions labeling was observed, the relative variation of mean fluorescence intensity returned to pretreatment levels indicating a complete abrogation of $70 \mathrm{kDa}$ FD leakage from blood vessels, thus resealing of blood vessel wall (Fig. 4C). The observed changes were not related to the initial diameter of the blood vessels, nor to the initial volume of CD31 labelled cell-to-cell junctions (Supp Fig. 5 and 6).

Because arteries, venules and capillaries differ in their structure and in their response to EP [24,25] we separately analyzed the modifications of endothelial cell-to-cell junctions' induced by EP for each category of blood vessels (Fig. 5A, D, G). Figure 5 illustrates the different effects induced by EP on blood vessels shape and on the volume of CD31 labelling in EC cell-to-cell junctions. The gradual and significant decrease in the volume of CD31 labelled voxels induced by EP was similar between arteries, venules and capillaries (Fig. 5B, $\mathrm{E}, \mathrm{H})$. This result demonstrates that just after EP the junctions between EC of these vessels are equally affected. Interestingly, $\sim 30 \mathrm{~min}$ after EP there was a "restoration" effect in the determined volume of CD31 labelled voxels in more than $50 \%$ of mice. This was observed in all three types of vessels, but it was more pronounced for venules and capillaries (Fig. 5B, E, H). However, it must be noted, that when comparing to the control mice, it took $\sim 90 \mathrm{~min}$ for the venules and capillaries to reach control levels in the group where the "restoration" was observed (Fig. 5F, I F), whereas, arteries regained only $~ 50 \%$ of the labelled volume in the same time (Fig. 5C). These results indicate that the response of all three blood vessels types to $\mathrm{EP}$ is specific. Venules and capillaries are more similar in their behavior after $\mathrm{EP}$ compared to arteries. The diffusion of $70 \mathrm{kDa} F D$ in the tissue after it leaked from blood 
vessels unable us to perform similar analysis for $70 \mathrm{kDa}$ FD leakage, as it was not possible to retrospectively determine which blood vessel was the source.
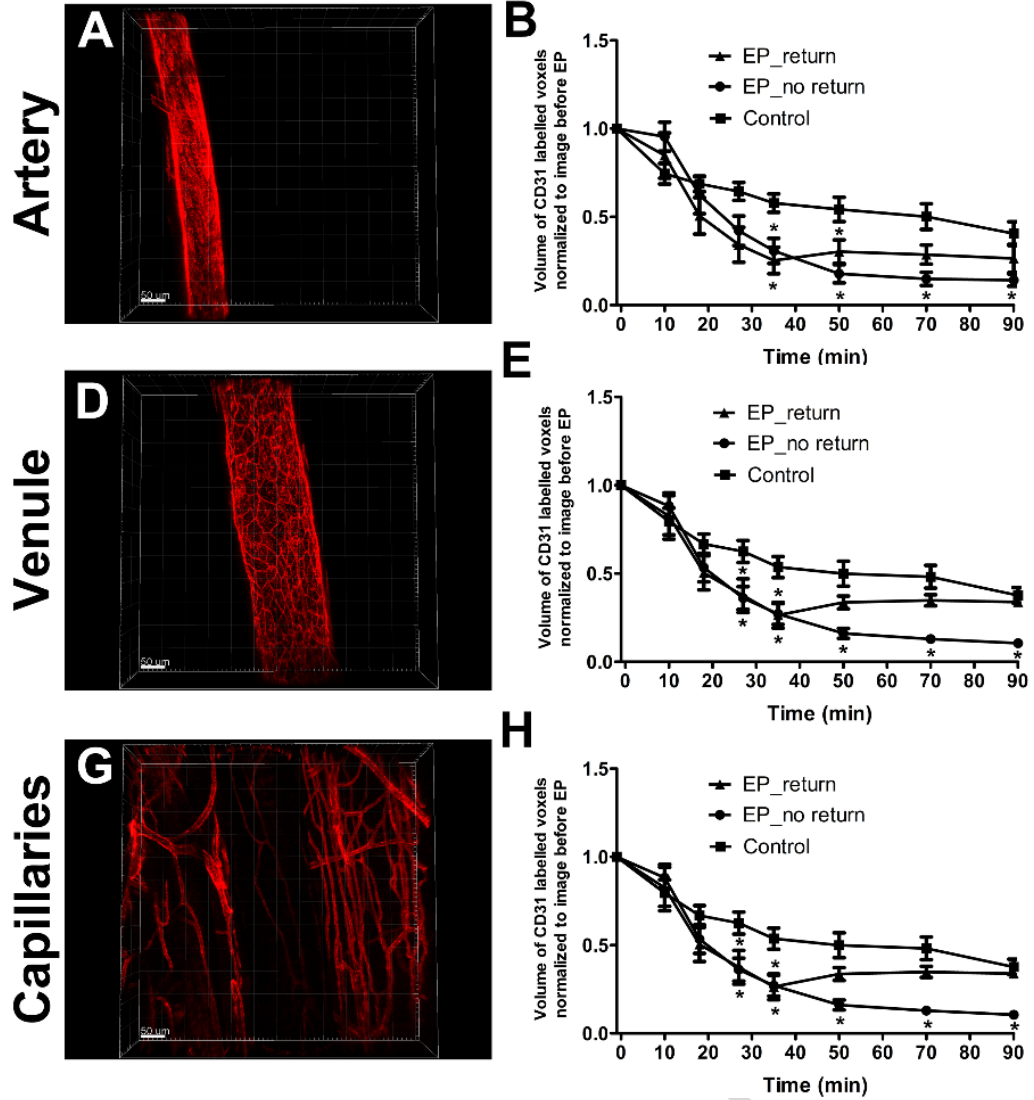
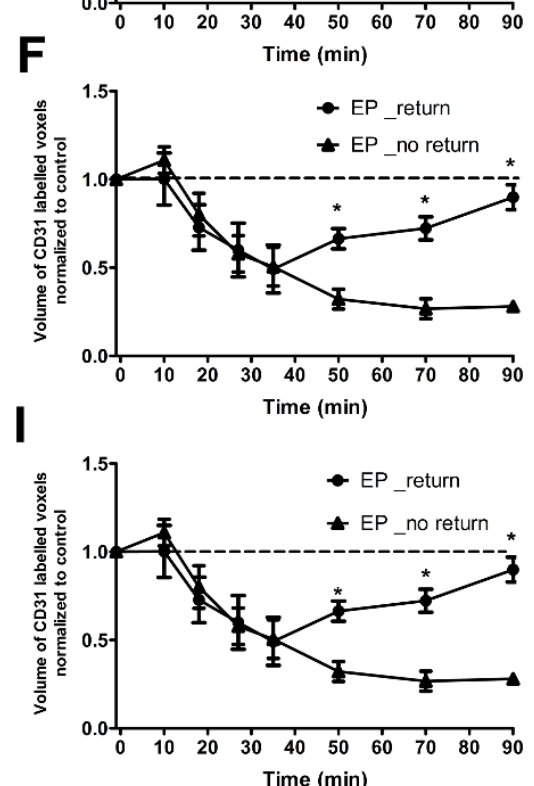

Fig. 5. Blood vessel type dependent changes in CD31 labelled cell-to-cell junctions volume after EP. The imaged $3 D$ volume was separated into 3 parts to include only arteriole $(A)$, venule $(D)$ or capillaries $(G)$ and the volume of CD31 labelled cell-to-cell junctions was plotted against time for each type of blood vessels $(B, E$, $H$ ). Eight square wave electric pulses, amplitude per distance $1300 \mathrm{~V} / \mathrm{cm}$, pulse length $100 \mu$ s, repetition frequency $1 \mathrm{~Hz}$, were applied in EP groups. Obtained volumes were normalized to the con trol level and plotted against time to correct for photobleaching $(C, F, I)$. Control - mice where no EP was applied $(n=12)$. $E P \_r e t u r n$ - mice where EP was applied and return of junctions was observed $(n=8), E P \_n o$ return - mice where EP was applied and no return of junctions was observed ( $n=7)$. Scale bar: $50 \mu m$. Error bars indicate SEM. ${ }^{*} P<0.05$ in comparison to control $(B, E, H)$ and $P<0.05$ in comparison to $E P \_$no return group $(C, F, I)$.

\subsection{In vivo effects of EP on the fluorophore linked to CD31 antibody}

To confirm that the reduction of the CD31 associated fluorescence intensity was due to a decrease in the number of detected CD31, it was needed to make sure that it was not associated to a decrease in the fluorophore quantum yield (modification of the environment or energy transfer) due to an alteration of the environment. The fluorescence emission for a given excitation intensity $\mathrm{I} 0$ is dependent on the number of emitting molecules $\mathrm{N}$ and on the fluorophore quantum yield $\Phi$ : If $=$ K I0 N $\Phi$.

The change in quantum yield can be accessed by the experimental evaluation of the fluorophore lifetime by FLIM. We looked at the modification of the fluorescence lifetime of Alexa Fluor 647 induced by EP. The choice of Alexa Fluor 647 was due to its longer lifetime compared to Alexa Fluor 555 ( 1 ns compared to $0.3 \mathrm{~ns}$ ) which was used in the rest of the study. Furthermore, a previous study reported that Alexa Fluor 647 conjugated to a kinase 
inhibitor could undergo changes in fluorescence lifetime between the free and bound states [31]. Thus, the change in fluorescence lifetime of Alexa Fluor 647 fluorophore, directly linked to its quantum yield, may be indicative of the changes in its environment and could result in a decreased fluorescence intensity, thus skewing the volumetric measurements of CD31 labelled cell-to-cell junctions.

In order to study whether the lifetime of Alexa 647 was modified, we i.v. injected Alexa 647 CD31 antibody and we performed FLIM 4h after the injection of antibodies. FLIM was performed before and after EP. The Alexa 647 fluorescence lifetime in cell-to-cell junctions was measured for each pixel by fitting the decay curve with a single-exponential model and represented by a heat map (Fig 6A, B). The measurement performed before and after EP did not show significant modification of Alexa 647 lifetime (and quantum yield $\Phi$ ) after EP (Fig. 6C). This result confirms that the loss of CD31 fluorescence intensity clearly reflects the decrease of $\mathrm{N}$ - the number of detected fluorophores - and thus an alteration of cell-to-cell junctions and is not due to a modification of the quantum yield of the fluorophore and thus a modification of its environment.

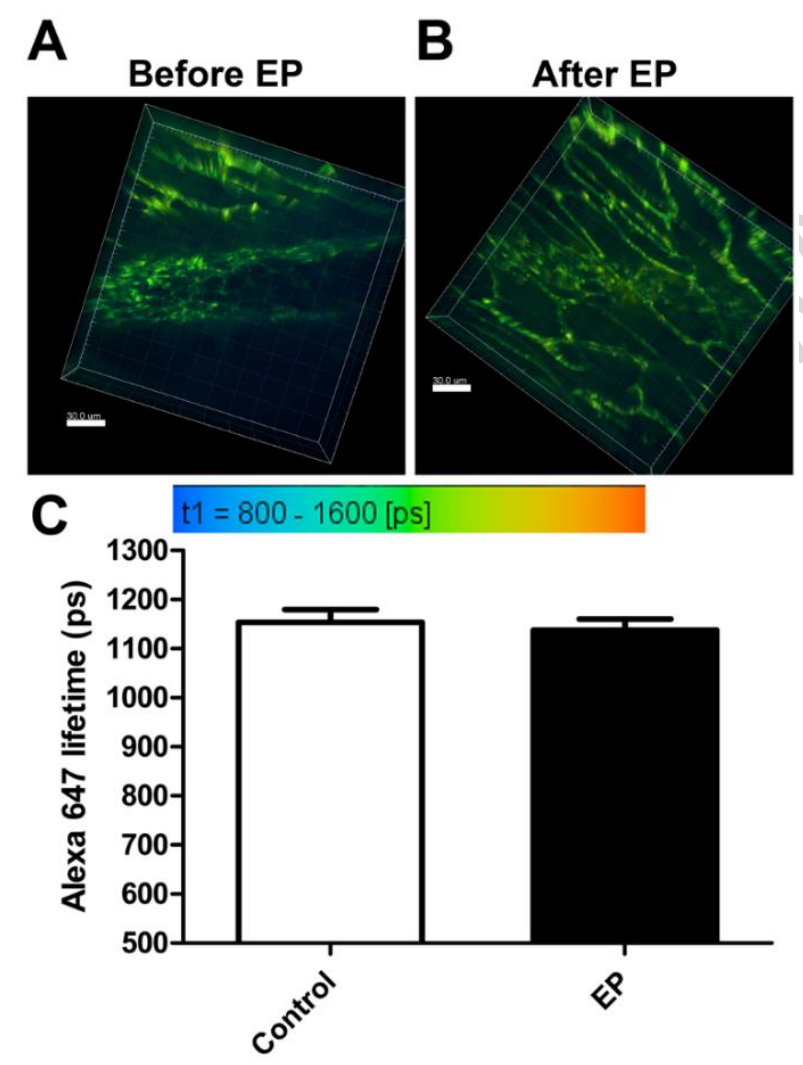

Fig 6. Fluorescence lifetime of Alexa 647 bound to anti-CD31 antibody before and after EP. Representative FLIM images of $3 D$ volumes before and after EP (13 min after EP) showing Alexa 647 lifetime in cell-to-cell junctions for each pixel. Alexa 647 lifetime is represented as a heat-map in picosecond (ps) (A and B). Scale bar: $30 \mu \mathrm{m}$. The measured mean Alexa 647 lifetime was not statistically significantly different before and after EP (C). Eight square wave electric pulses, amplitude per distance $1300 \mathrm{~V} / \mathrm{cm}$, pulse length $100 \mu$ s, repetition frequency $1 \mathrm{~Hz}$, were applied in EP groups $(n=3)$.

\subsection{In vitro effects of EP on endothelial cell-to-cell junction proteins}


To further confirm the alteration in cell-to-cell junctions after EP, we observed in vitro how were the endothelial junctional proteins affected by EP. We used a murine endothelial cell line bEnd.3 grown in monolayers and performed immunofluorescence staining with CD31 and VE-cadherin fluorescently labelled antibodies, before and at different times after EP. We used VE-cadherin as a second endothelial junctional protein due to poor expression of CD31 in majority of in vitro endothelial cell cultures [32,33].

We observed a transient but significant decrease of CD31 and VE-cadherin fluorescence intensity in the endothelial cell-to-cell junctions after EP (Figure 7) which returned to the levels similar or higher than in the control non-treated cells within 20 min after EP (Fig. 7C). These in vitro experiments recapitulate our in vivo results where we observed a transient decrease of CD31 positive voxels in the endothelial cell-to-cell junctions after EP in the group of mice where the return of cell-to-cell junctions appeared (Fig. 4). Moreover, often clearly visible gaps between the endothelial cells appeared after EP, indicating that in some instances, the cell-to-cell junctions were completely disassembled (Fig. 7B), which may indicate a significant damage to those junctions and provide an explanation for the group of mice where the return of endothelial cell-to-cell junctions was not observed (Fig. 2, 4). 


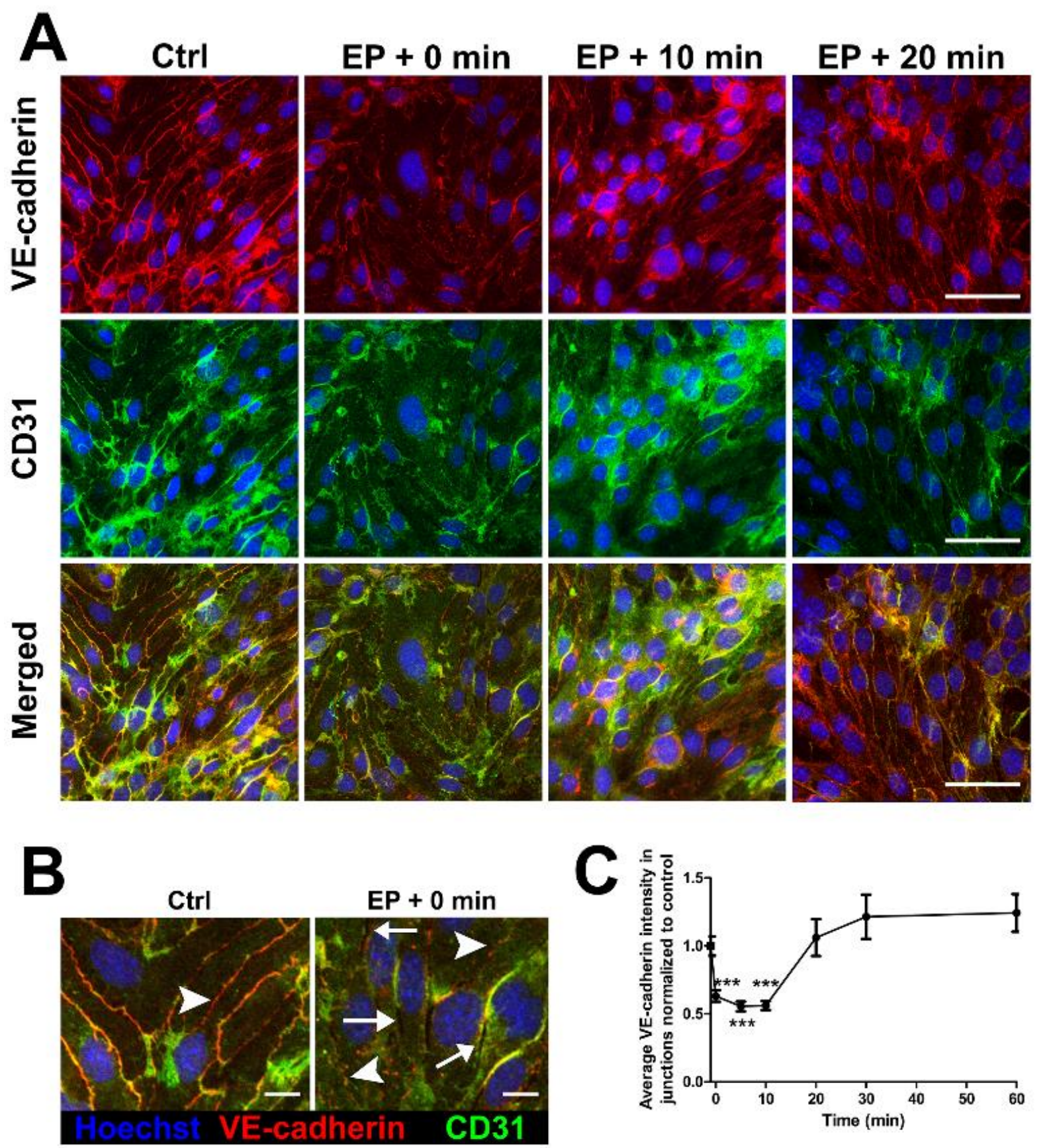

Fig 7. Transient disruption of endothelial cell-to-cell junctions after EP in vitro. Representative confocal images $(6 A, B)$ of VE-cadherin and CD31 staining in murine endothelial cells bEnd.3 grown in vitro and exposed to EP ( 8 square wave electric pulses, amplitude per distance $600 \mathrm{~V} / \mathrm{cm}$, pulse length $100 \mu \mathrm{s}$, repetition frequency $1 \mathrm{~Hz}$, distance between electrodes $7.3 \mathrm{~mm}$ ) at designated times after EP. In (B) higher power images of both intact endothelial cell-to-cell junctions (arrowhead) and EP induced gaps (arrows) are shown. The quantification of the changes in average VE-cadherin fluorescence intensity in cell-to-cell junctions plotted at different times after $\operatorname{EP}(C)$. Data is presented as mean \pm SEM. *** $P<0.001$. Scale bar: $50 \mu \mathrm{m}(A), 10 \mu \mathrm{m}(B)$.

Taken together, this data demonstrates that a rearrangement of endothelial junctional proteins appears after EP implying on a disruption of the barrier function of the endothelium, which is probably the main reason for the increased permeability of the blood vessel wall after EP. 


\section{DISCUSSION}

In this study, we aim to study in vivo alteration of endothelial cell-to-cell junctions occurring after EP. Our experimental setting using DWC models in mice in combination with multiphoton microscopy allowed direct observation of blood vessels at the single endothelial cell level in 3D. By doing so, we could measure in situ the alterations in cell-to-cell junctions and correlate them to the previously known changes in blood vessel permeability after EP [24,25]. Delivery of validated EP parameters used in clinical applications [11] to normal tissue (skin) led to an immediate constriction of blood vessels which correlated with the change in the shape of EC. This was followed by an increase in permeability of blood vessels for $70 \mathrm{kDa} F D$ and a decrease in the volume of CD31 labelled cell-to-cell junctions. Interestingly, both the permeability of blood vessels and the volume of CD31 labelled cell-tocell junctions returned to initial values in only $50 \%$ of the treated mice, whereas in the others it did not.

First, we set out to confirm that previously reported findings of the effects of EP on blood vessels can be observed using our model. We used a fluorescently labelled antibody targeting CD31 to label the endothelial cell-to-cell junctions and used multiphoton microscopy to confirm the previously reported changes in the blood vessels diameters after $\mathrm{EP}$ in 3D (Fig. 3) [24,25]. Indeed, the reduction of the diameter of both arteries and venules was observed after EP (Fig. 3); however, due to the temporal limitation of the imaging technique we were not able to follow this in more detail. Fluorescently labelled CD31 antibodies have already been used to label endothelial cell-to-cell junctions in vivo, however, not for the purpose to follow spatiotemporal changes of single EC in DWC model $[34,35]$. Currently, the first phase of vascular response to EP is attributed to direct smooth muscle cells electrical field stimulation and followed by indirect sympathetically-mediated vasoconstriction acting on smooth muscles of afferent arteries, leading to a rapid and profound but short-lived initial decrease in blood flow [15]. Nevertheless, venules are also affected but to a lesser extent [24,25,27]. This short-lived vasoconstriction was shown to last up to $8 \mathrm{~min}$ and resulted in a so-called vascular lock effect, i.e. abrogation of blood flow [24]. Despite the temporal limitations of our approach we were still able to confirm that vasoconstriction after EP is detectable in our model. Furthermore, we provide for the first time the evidence that the change in the diameter of blood vessels after EP is associated with a change in the shape of EC, both in venules and in arteries in $3 \mathrm{D}$ in vivo (Fig. 3).

Then, we used an i.v. injected $70 \mathrm{kDa} F D$ as a model molecule for drugs and oligonucleotides [36] and confirmed in 3D the increase of permeability of blood vessels after EP for this size of molecules (Fig. 2). As previously reported, EP increases permeability of blood vessels for various sizes of macromolecules spanning up to $2000 \mathrm{kDa}$, which implies that this technique could be used for increased local delivery of a plethora of drugs including nanoparticles or PEGylated liposomes [24]. All of the mice where EP was applied showed statistically significantly increased permeability for $70 \mathrm{kDa} F D$; however, we observed a separation of the scale of their response into 2 distinct groups. The first group of mice $(n=7)$ showed a high increase in the permeability of blood vessels, demonstrated by $>600 \%$ change in relative mean fluorescence intensity compared to pretreatment values, whereas the second group $(n=8)$ showed only a moderate increase in the permeability ( $60 \%$ change in relative 
mean fluorescence intensity compared to pretreatment values). As this was not yet reported in the literature, we decided to more closely investigate this phenomenon.

Based on the published in vitro studies showing reversible structural changes of the cytoskeleton and cell junctions concomitant with a rapid rise in endothelial monolayer permeability [28,37,38] and histological analysis of early time points of the tissues exposed to EP, showing alterations in the shape of EC [8,25,27], we chose to more closely inspect the changes in the endothelial cell-to-cell junctions. Additionally, recent reports showed that magnetic forces can increase the permeability of blood vessels by disrupting endothelial cellto-cell junctions [39]. Therefore, we decided to follow the changes in the volume of CD31 labelled junctions after EP with time and showed that, indeed, the cell-to-cell junctions are affected by EP (Fig. 4, 5). We have shown that the volume of CD31 labelled junctions is reduced after EP and that we could see the same separation into 2 distinct groups as was the case with the increase in the permeability of blood vessels for $70 \mathrm{kDa} F D$ (Fig. 4). In the group of mice where the increase of permeability was moderate, we have observed that the volume of CD31 labelled junctions' returns to the levels comparable to the control group and that the turning point is $\sim 30 \mathrm{~min}$ after $\mathrm{EP}$, which coincides with the decrease in the permeability of blood vessels for $70 \mathrm{kDa} F D$ (Fig. 4B). In contrast, in the group of mice where there was a high increase in the permeability of blood vessels the volume of the CD31 labelled junctions was decreasing throughout the observation period (Fig. 4C). However, similarly as in the first group, at $\sim 30 \mathrm{~min}$ after EP, there was a change in the rate of disappearance of the labelled junctions that coincided with the decrease in the permeability of blood vessels for $70 \mathrm{kDa}$ FD (Fig. 4C). To further elaborate whether this measurement could be over-dependent on a certain type of blood vessels, we have separately analyzed the effect of $\mathrm{EP}$ on the volume of CD31 labelled cell-to-cell junctions in arteries, venules, and capillaries and showed that they respond in a similar manner (Fig. 5). Moreover, we confirmed using FLIM that the observed changes in the quantified volume of CD31 labelled cell-to-cell junctions are not due to a modification that EP would cause to the environment of the fluorophore attached to the CD31 antibody, as was indicated by the fluorophore retaining the same fluorescence lifetime as before EP (Fig 6). An explanation for the observed decrease in the volume of CD31 labelled junctions could be that CD31 (PECAM-1) is constantly recycled and it can take up to $30 \mathrm{~min}$ in vitro to completely replenish the cell-to-cell junctions with CD31 [40,41], or alternatively it is redistributed in the cellular membrane. This is in line with the hypothesis that EP disrupts the endothelial junctions and then CD31 is either recycled back to the endothelial membrane or redistributed back to the junctions, which was confirmed by our in vivo observations in the group where we have seen the return of CD31 labelling. We confirmed this phenomenon in our in vitro experiments with murine endothelial cells bEnd.3 grown as monolayers, where EP transiently reduced the quantity of VE-cadherin present in the cell-to-cell junctions, which has returned to control levels within 20 min after EP (Fig. 7). This shows, that the predominant reason for the in vivo observed return of CD31 labelling after EP is the re-establishment of endothelial cell-to-cell junctions and not the relabelling of CD31 proteins by the remaining circulating antibody (half-life of rat IgG2a antibodies can be more than 4 days [42]). Notably, we have also observed presence of gaps between the endothelial cells after EP, which were still present even $20 \mathrm{~min}$ after EP, but 
absent in control non-treated monolayers (Fig. 7B). These gaps would indicate an extensive damage and complete disassembly of the endothelial cell-to-cell junctions and might be the main channel through which macromolecules extravasate after EP. Conversely, they might explain the behavior of the second group of mice where we did not see the return of CD31 labelled cell-to-cell junctions. Another possible explanation for the observed differences between the two groups of mice could also be the result of the heterogeneity of the electric field distribution in tissues, which would then result in local differences in response to EP. As our field of view in IVMM was only $\sim 1.6 \%(\sim 0.5 \times 0.5 \mathrm{~mm})$ of the entire affected area, we could be imaging areas that were more or less affected by EP. A further proof to the heterogeneity of the response of blood vessels to EP is the stochastic focal aggregation of platelets on blood vessel walls (Supp Fig. 7), which would imply that there is a difference in the extent of the disruption of cell-to-cell junctions within the same mouse/vessel. One possible explanation for the reduction of the CD31 labelling in the cell-to-cell junctions could also be the inactivation of the Rho kinase [28]. Kanthou et al showed that EP besides destabilizing the endothelial cytoskeleton also reduces the basal levels of phosphorylated myosin light chains implicating Rho kinase inactivation [28]. As activation of Rho proteins necessitates their translocation and association with membrane components it is likely that EP inactivates Rho by preventing its association with the cell membrane, thus preventing the reestablishment of cell-to-cell junctions after EP, which could consequently lead to internalization of CD31 as it is no longer in a homophilic CD31/CD31 interactions between neighboring endothelial cells [43].

The currently proposed model of the effects of EP on blood vessels is a two-phase model. In this model, the second phase, based on the data obtained in muscle, was attributed to the permeabilization of muscle fibers and endothelial cell membranes due to EP leading to increased interstitial pressure and decreased intravascular pressure. This model also suggests that the increase in the permeability of blood vessels can be attributed to the increase in the permeability of the membranes of EC, which are indeed exposed to higher electric field strength than surrounding tissue $[8,15]$. This prediction was based on the resealing kinetics of cellular membranes after EP in vitro and in vivo, which were shown to be in the order of 10 $\min [15,44,45]$. Moreover, it was already shown that the increased permeability of blood vessels after EP, even for large macromolecules, can actually persist longer than it can be explained solely by the membrane resealing kinetics after EP [24,25]. Even in in vitro settings, where it is well established that membrane resealing after EP is completed within 10 min after EP, otherwise the cell is regarded as irreversibly electroporated, it was repeatedly shown that monolayers of EC still have increased permeability for macromolecules even 40 min after EP [28,37,38]. Those in vitro investigations pinpointed endothelial cell-to-cell junctions as a possible mechanism responsible for the observed increased permeability of blood vessels in vivo [28]. We now provide a direct in vivo proof on the level of single EC that the alterations in endothelial cell-to-cell junctions after EP are the main mechanism responsible for the observed increased permeability of blood vessels for macromolecules, which was demonstrated by the strong correlation between extravasation of $70 \mathrm{kDa}$ FD from 
blood vessels and the changes in the volume of CD31 labelled cell-to-cell junctions. Although, our investigations can conclusively show the importance of cell-to-cell junctions in the increased permeability of normal blood vessels, this may not necessarily reflect the changes in the tumor vasculature. However, as one of the main hallmarks of tumor vasculature is that it is inherently leaky and does not have proper organization of endothelial cell-to-cell junctions, the effects of EP on their organization might be diminished or even absent. Additionally, as previously shown, the main effect of EP on tumor vasculature is a profound and long lasting vascular lock, which lasts longer than the disruption of the cell-tocell junctions that was observed in current study [17].

The intriguing finding of this study is the separation of mice where EP was applied into 2 distinct groups: a group with moderate increase in permeability and return of labelled cell-to-cell junctions and a group with high increase in permeability and without any return of labelled cell-to-cell junctions. As mentioned before, the return of the CD31 labelling in the first group could be explained with the CD31 recycling hypothesis, but this cannot explain the observed behavior in the second group. The first hallmark of the second group is a high increase in permeability of blood vessels for $70 \mathrm{kDa} F D$ after EP, which indicates that the integrity of blood vessel wall was significantly perturbed and that molecules from the surrounding tissue can gain access to the circulating blood as well. This was confirmed previously and it can be exploited for systemic delivery of macromolecules after local application of EP to the skin. [46]. But this also shows that macromolecules such as collagen and tissue factor (TF), which are a key component of platelet activation pathway [47-49], are exposed to the circulating blood after EP. Both molecules serve as a defense against perturbations in the blood vessel wall, collagen acting as a first line defense and TF as a second line of defense, but both of them, once in contact with circulating blood, trigger the platelet activation pathway. The first step in platelet activation pathway is attachment of platelets to the blood vessel wall at the site of the "injury" and once activated they further propagate clot formation [48]. In the case, when the cell-to-cell junctions are sufficiently perturbed, the forming clot fills the gap between neighboring cells to prevent leakage of macromolecules from blood vessels. However, this process is not immediate and is dependent on the size of the injury [48,49]. The activation of platelets and formation of clots could be the reason for the observed lack of the return of labelled junctions in our settings, as the formation of a clot and its binding into the cell-to-cell junctions would prevent the internalized labelled CD31 to be recycled back into the cell-to-cell junction. Indeed this is what we have seen in our experiments, where labeled platelets formed clots at the blood vessel wall after EP (Supp Fig. 7). Interestingly, clots were formed stochastically, implying that the effect of EP on blood vessel permeability and disruption of cell-to-cell junctions is heterogeneous even within the same mouse. Furthermore, the areas associated to platelet aggregation had a higher increase of permeability of blood vessel wall as indicated by increased leakage of $70 \mathrm{kDa} F D$. The subsequent event after platelet activation and clot formation is local inflammation, which can increase permeability of blood vessels for a prolonged period of time, as was observed previously and confirmed in our study [8,25]. Local inflammation also recruits leukocytes to the site of injury [50], which was previously confirmed when EP was applied to normal skin that can then facilitate uptake and 
presentation of new antigens to the host immune system. This mechanism is currently exploited in DNA vaccination, where EP dramatically increases its effectiveness and it could also be exploited in combination with immunotherapy [51-53].

\section{CONCLUSIONS}

The use of EP to deliver a wide range of macromolecules, ranging from cytostatic drugs to plasmid DNA, to either normal tissue or to tumors is expanding [52,54]. However, the underlying mechanisms that are essentially a tissue specific response to EP remain poorly understood. To our best knowledge, our study shows for the first time in vivo in 3D on a single EC level that alterations in endothelial cell-to-cell junctions play an important role in the response of blood vessels to EP. Furthermore, this event alone could possibly trigger the platelet activation cascade and formation of clots, leading to local inflammation. Thus, knowledge of the vascular response to EP at early as well as at late time points after EP can lead to better planning of EP based treatment as well as providing new potential targets for increasing the efficacy of either delivery of macromolecules to tissues or increasing DNA vaccination efficiency.

\section{ACKNOWLEDGMENTS}

Research was conducted in the scope of LEA EBAM (French Slovenian European Associated Laboratory: Pulsed Electric Fields Applications in Biology and Medicine) and COST Action TD1104. The authors acknowledge the financial support from the state budget by the Slovenian Research Agency (program no. P3-0003 and P4-0053, project no. J3-6793, J36796, J3-5505), the "Toulouse Réseau Imagerie and Anexplo" core IPBS facilities support (Genotoul, Toulouse, France) which was supported by the Association Recherche Cancer ( ${ }^{\circ}$ 5585), Region Midi Pyrenees (CPER) and Grand Toulouse cluster. The Midi-Pyrenees Region has financially supported this work (Grant 11052700).

\section{DISCLOSURES}

The authors have no relevant financial interest or financial conflict apart from those disclosed. 


\section{REFERENCES}

[1] D. Alex, E.C. Leong, Z.-J. Zhang, G.T.H. Yan, S.-H. Cheng, C.-W. Leong, et al., Resveratrol derivative, trans-3,5,4'-trimethoxystilbene, exerts antiangiogenic and vascular-disrupting effects in zebrafish through the downregulation of VEGFR2 and cell-cycle modulation., J. Cell. Biochem. 109 (2010) 339-46. doi:10.1002/jcb.22405.

[2] Z. Jiang, M. Wu, J. Miao, H. Duan, S. Zhang, M. Chen, et al., Deoxypodophyllotoxin exerts both anti-angiogenic and vascular disrupting effects., Int. J. Biochem. Cell Biol. 45 (2013) 1710-9. doi:10.1016/j.biocel.2013.04.030.

[3] E. Pasquier, S. Sinnappan, M.A. Munoz, M. Kavallaris, ENMD-1198, a new analogue of 2-methoxyestradiol, displays both antiangiogenic and vascular-disrupting properties., Mol. Cancer Ther. 9 (2010) 1408-18. doi:10.1158/1535-7163.MCT-090894.

[4] X. Ren, M. Dai, L.-P. Lin, P.-K. Li, J. Ding, Anti-angiogenic and vascular disrupting effects of C9, a new microtubule-depolymerizing agent., Br. J. Pharmacol. 156 (2009) 1228-38. doi:10.1111/j.1476-5381.2009.00112.x.

[5] T. Dolinsek, B. Markelc, G. Sersa, A. Coer, M. Stimac, J. Lavrencak, et al., Multiple Delivery of siRNA against Endoglin into Murine Mammary Adenocarcinoma Prevents Angiogenesis and Delays Tumor Growth, PLoS One. 8 (2013).

[6] T. Dolinsek, B. Markelc, M. Bosnjak, T. Blagus, L. Prosen, S. Kranjc, et al., Endoglin silencing has significant antitumor effect on murine mammary adenocarcinoma mediated by vascular targeted effect., Curr. Gene Ther. 15 (2015) 228-44. http://www.ncbi.nlm.nih. gov/pubmed/25619888 (accessed June 21, 2015).

[7] G. Sersa, M. Krzic, M. Sentjurc, T. Ivanusa, K. Beravs, V. Kotnik, et al., Reduced blood flow and oxygenation in SA-1 tumours after electrochemotherapy with cisplatin., Br. J. Cancer. 87 (2002) 1047-54. doi:10.1038/sj.bjc.6600606.

[8] G. Sersa, T. Jarm, T. Kotnik, A. Coer, M. Podkrajsek, M. Sentjurc, et al., Vascular disrupting action of electroporation and electrochemotherapy with bleomycin in murine sarcoma., Br. J. Cancer. 98 (2008) 388-98. doi:10.1038/sj.bjc.6604168.

[9] E. Neumann, M. Schaefer-Ridder, Y. Wang, P.H. Hofschneider, Gene transfer into mouse lyoma cells by electroporation in high electric fields., EMBO J. 1 (1982) 841-5. http://www.pubmedcentral. nih.gov/articlerender.fcgi?artid=553119\&tool=pmcentrez\& rendertype=abstract (accessed April 11, 2016).

[10] L.M. Mir, H. Banoun, C. Paoletti, Introduction of definite amounts of nonpermeant molecules into living cells after electropermeabilization: direct access to the cytosol., Exp. Cell Res. 175 (1988) 15-25. http://www.ncbi.nlm.nih.gov/pubmed/3345798.

[11] M. Marty, G. Sersa, J.R. Garbay, J. Gehl, C.G. Collins, M. Snoj, et al., Electrochemotherapy - An easy, highly effective and safe treatment of cutaneous and subcutaneous metastases: Results of ESOPE (European Standard Operating Procedures of Electrochemotherapy) study, Eur. J. Cancer Suppl. 4 (2006) 3-13. doi:10.1016/j.ejcsup.2006.08.002.

[12] L.G. Campana, A.J.P. Clover, S. Valpione, P. Quaglino, J. Gehl, C. Kunte, et al., Recommendations for improving the quality of reporting clinical electrochemotherapy studies based on qualitative systematic review., Radiol. Oncol. 50 (2016) 1-13. 
doi:10.1515/raon-2016-0006.

[13] G. Sersa, M. Cemazar, D. Miklavcic, Antitumor effectiveness of electrochemotherapy with cis-diamminedichloroplatinum(II) in mice., Cancer Res. 55 (1995) 3450-5. http://www.ncbi.nlm.nih.gov/pubmed/7614485 (accessed May 1, 2016).

[14] S. Orlowski, J. Belehradek, C. Paoletti, L.M. Mir, Transient electropermeabilization of cells in culture. Increase of the cytotoxicity of anticancer drugs., Biochem. Pharmacol. 37 (1988) 4727-33. http://www.ncbi.nlm.nih.gov/pubmed/2462423 (accessed May 1, 2016).

[15] J. Gehl, T. Skovsgaard, L.M. Mir, Vascular reactions to in vivo electroporation: characterization and consequences for drug and gene delivery., Biochim. Biophys. Acta. 1569 (2002) 51-8. http//www.ncbi.nlm.nih.gov/pubmed/11853957 (accessed May 1, 2016).

[16] G. Sersa, M. Cemazar, D. Miklavcic, D.J. Chaplin, Tumor blood flow modifying effect of electrochemotherapy with bleomycin., Anticancer Res. 19 (1999) 4017-22. http://www.ncbi.nlm.nih. gov/pubmed/10628347 (accessed May 1, 2016).

[17] B. Markelc, G. Sersa, M. Cemazar, Differential mechanisms associated with vascular disrupting action of electrochemotherapy: intravital microscopy on the level of single normal and tumor blood vessels., PLoS One. 8 (2013) e59557. doi:10.1371/journal.pone.0059557.

[18] M. Snoj, M. Cemazar, T. Srnovrsnik, S.P. Kosir, G. Sersa, Limb sparing treatment of bleeding melanoma recurrence by electrochemotherapy., Tumori. 95 (2009) 398-402. http://www.ncbi.nlm.nih.gov/pubmed/19688986 (accessed May 1, 2016).

[19] B. Agerholm-Larsen, H.K. Iversen, P. Ibsen, J.M. Moller, F. Mahmood, K.S. Jensen, et al., Preclinical validation of electrochemotherapy as an effective treatment for brain tumors., Cancer Res. 71 (2011) 3753-62. doi:10.1158/0008-5472.CAN-11-0451.

[20] I. Edhemovic, E. Brecelj, G. Gasljevic, M. Marolt Music, V. Gorjup, B. Mali, et al., Intraoperative electrochemotherapy of colorectal liver metastases., J. Surg. Oncol. 110 (2014) 320-7. doi:10.1002/jso.23625.

[21] A. Al-Khadra, V. Nikolski, I.R. Efimov, The role of electroporation in defibrillation., Circ. Res. 87 (2000) 797-804. http://www.ncbi.nlm.nih. gov/pubmed/11055984 (accessed April 30, 2016).

[22] B. Mali, T. Jarm, S. Corovic, M.S. Paulin-Kosir, M. Cemazar, G. Sersa, et al., The effect of electroporation pulses on functioning of the heart., Med. Biol. Eng. Comput. 46 (2008) 745-57. doi:10.1007/s11517-008-0346-7.

[23] B. Mali, V. Gorjup, I. Edhemovic, E. Brecelj, M. Cemazar, G. Sersa, et al., Electrochemotherapy of colorectal liver metastases--an observational study of its effects on the electrocardiogram., Biomed. Eng. Online. 14 Suppl 3 (2015) S5. doi:10.1186/1475-925X-14-S3-S5.

[24] E. Bellard, B. Markelc, S. Pelofy, F. Le Guerroué, G. Sersa, J. Teissié, et al., Intravital microscopy at the single vessel level brings new insights of vascular modification mechanisms induced by electropermeabilization, J. Control. Release. 163 (2012) 396403.

[25] B. Markelc, E. Bellard, G. Sersa, S. Pelofy, J. Teissie, A. Coer, et al., In vivo molecular imaging and histological analysis of changes induced by electric pulses used 
for plasmid DNA electrotransfer to the skin: a study in a dorsal window chamber in mice., J. Membr. Biol. 245 (2012) 545-54. doi:10.1007/s00232-012-9435-5.

[26] S. Corovic, B. Markelc, M. Dolinar, M. Cemazar, T. Jarm, Modeling of microvascular permeability changes after electroporation., PLoS One. 10 (2015) e 0121370. doi:10.1371/journal.pone.0121370.

[27] T. Jarm, M. Cemazar, D. Miklavcic, G. Sersa, Antivascular effects of electrochemotherapy: implications in treatment of bleeding metastases., Expert Rev. Anticancer Ther. 10 (2010) 729-46. doi:10.1586/era.10.43.

[28] C. Kanthou, S. Kranjc, G. Sersa, G. Tozer, A. Zupanic, M. Cemazar, The end othelial cytoskeleton as a target of electroporation-based therapies., Mol. Cancer Ther. 5 (2006) 3145-52. doi:10.1158/1535-7163.MCT-06-0410.

[29] S.J. Lunt, C. Gray, C.C. Reyes-Aldasoro, S.J. Matcher, G.M. Tozer, Application of intravital microscopy in studies of tumor microcirculation., J. Biomed. Opt. 15 (2010) 11113. doi:10.1117/1.3281674.

[30] W. Becker, Fluorescence lifetime imaging--techniques and applications., J. Microsc. 247 (2012) 119-36. doi:10.1111/j.1365-2818.2012.03618.x.

[31] C.S. Lebakken, Hee Chol Kang, K.W. Vogel, A Fluorescence Lifetime-Based Binding Assay to Characterize Kinase Inhibitors, J. Biomol, Screen. 12 (2007) 828-841. doi:10.1177/1087057107304480.

[32] R.C. Brown, A.P. Morris, R.G. O’Neil, Tight junction protein expression and barrier properties of immortalized mouse brain microvessel endothelial cells., Brain Res. 1130 (2007) 17-30. doi:10.1016/j.brainres.2006.10.083.

[33] L. Song, J.S. Pachter, Culture of murine brain microvascular endothelial cells that maintain expression and cytoskeletal association of tight junction-associated proteins., In Vitro Cell. Dev. Biol. Anim. 39 (2003) 313-20. doi:10.1290/1543706X(2003)039<0313:COMBME>2.0.CO;2.

[34] D. Proebstl, M.-B. Voisin, A. Woodfin, J. Whiteford, F. D’Acquisto, G.E. Jones, et al., Pericytes support neutrophil subendothelial cell crawling and breaching of venular walls in vivo., J. Exp. Med. 209 (2012) 1219-34. doi:10.1084/jem.20111622.

[35] M. Khurana, E.H. Moriyama, A. Mariampillai, B.C. Wilson, Intravital high-resolution optical imaging of individual vessel response to photodynamic treatment., J. Biomed. Opt. 13 (2008) 40502. doi:10.1117/1.2965545.

[36] A. Paganin-Gioanni, E. Bellard, J.M. Escoffre, M.P. Rols, J. Teissié, M. Golzio, Direct visualization at the single-cell level of siRNA electrotransfer into cancer cells., Proc. Natl. Acad. Sci. U. S. A. 108 (2011) 10443-7. doi:10.1073/pnas.1103519108.

[37] C.J.W. Meulenberg, V. Todorovic, M. Cemazar, Differential cellular effects of electroporation and electrochemotherapy in monolayers of human microvascular endothelial cells., PLoS One. 7 (2012) e52713. doi:10.1371/journal.pone.0052713.

[38] C.J.W. Meulenberg, M. Cemazar, Low-magnification image analys is of Giemsa stained, electroporation and bleomycin treated endothelial monolayers provides reliable monolayer integrity data., Toxicol. In Vitro. 28 (2014) 502-9. doi:10.1016/j.tiv.2013.12.020.

[39] Y. Qiu, S. Tong, L. Zhang, Y. Sakurai, D.R. Myers, L. Hong, et al., Magnetic forces enable controlled drug delivery by disrupting endothelial cell-cell junctions, Nat. 
Commun. 8 (2017) 15594. doi:10.1038/ncomms15594.

[40] Z. Mamdouh, X. Chen, L.M. Pierini, F.R. Maxfield, W.A. Muller, Targeted recycling of PECAM from endothelial surface-connected compartments during diapedesis., Nature. 421 (2003) 748-53. doi:10.1038/nature01300.

[41] S. Muro, R. Wiewrodt, A. Thomas, L. Koniaris, S.M. Albelda, V.R. Muzykantov, et al., A novel endocytic pathway induced by clustering endothelial ICAM-1 or PECAM1., J. Cell Sci. 116 (2003) 1599-609. doi:10.1242/jcs.00367.

[42] J. V Peppard, E. Orlans, The biological half-lives of four rat immunoglobulin isotypes., Immunology. 40 (1980) 683-6. http://www.ncbi.nlm.nih.gov/pubmed/7429545 (accessed October 17, 2017).

[43] J.R. Privratsky, P.J. Newman, PECAM-1: regulator of endothelial junctional integrity., Cell Tissue Res. 355 (2014) 607-19. doi:10.1007/s00441-013-1779-3.

[44] G. Pucihar, T. Kotnik, D. Miklavcic, J. Teissié, Kinetics of transmembrane transport of small molecules into electropermeabilized cells., Biophys. J. 95 (2008) 2837-48. doi:10.1529/biophysj.108.135541.

[45] J.-M. Escoffre, E. Bellard, C. Faurie, S.C. Sébaï, M. Golzio, J. Teissié, et al, Membrane disorder and phospholipid scrambling in electropermeabilized and viable cells., Biochim. Biophys. Acta. 1838 (2014) 1701-9. doi:10.1016/j.bbamem.2014.02.013.

[46] T. Blagus, B. Markelc, M. Cemazar, T. Kosjek, V. Preat, D. Miklavcic, et al., In vivo real-time monitoring system of electroporation mediated control of transdermal and topical drug delivery, J. Control. Release. 172 (2013) 862-871.

[47] A.F. Stein-Merlob, C.W. Kessinger, S.S. Erdem, H. Zelada, S.A. Hilderbrand, C.P. Lin, et al., Blood Accessibility to Fibrin in Venous Thrombosis is Thrombus AgeDependent and Predicts Fibrinolytic Efficacy: An In Vivo Fibrin Molecular Imaging Study., Theranostics. 5 (2015) 1317-27. doi:10.7150/thno.12494.

[48] B. Furie, B.C. Furie, Mechanisms of thrombus formation., N. Engl. J. Med. 359 (2008) 938-49. doi:10.1056/NEJMra0801082.

[49] K.G. Mann, K. Brummel-Ziedins, T. Orfeo, S. Butenas, Models of blood coagulation., Blood Cells. Mol. Dis. 36 (2006) 108-17. doi:10.1016/j.bcmd.2005.12.034.

[50] R.M. Rao, L. Yang, G. Garcia-Cardena, F.W. Luscinskas, Endothelial-dependent mechanisms of leukocyte recruitment to the vascular wall., Circ. Res. 101 (2007) 23447. doi:10.1161/CIRCRES AHA.107.151860b.

[51] M. Sällberg, L. Frelin, G. Ahlén, M. Sällberg-Chen, Electroporation for therapeutic DNA vaccination in patients., Med. Microbiol. Immunol. 204 (2015) 131-5. doi:10.1007/s00430-014-0384-8.

[52] G. Sersa, J. Teissie, M. Cemazar, E. Signori, U. Kamensek, G. Marshall, et al, Electrochemotherapy of tumors as in situ vaccination boosted by immunogene electrotrans fer., Cancer Immunol. Immunother. 64 (2015) 1315-27. doi:10.1007/s00262-015-1724-2.

[53] C.Y. Calvet, L.M. Mir, The promising alliance of anti-cancer electrochemotherapy with immunotherapy., Cancer Metastasis Rev. (2016). doi:10.1007/s10555-016-96153 .

[54] M.L. Yarmush, A. Golberg, G. Sersa, T. Kotnik, D. Miklavcic, Electroporation-based 
technologies for medicine: principles, applications, and challenges., Annu. Rev. Biomed. Eng. 16 (2014) 295-320. doi:10.1146/annurev-bioeng-071813-104622. 
Supp Fig. 1. Timeline of changes in diameter of venules, arteries and capillaries after EP. The reduction of diameter of artery (straight large vessel without obvious EC cell shape), venule (large vessel with obvious EC cell shape) and capillaries (small vessels) after EP. Eight square wave electric pulses, amplitude per distance $1300 \mathrm{~V} / \mathrm{cm}$, pulse length $100 \mu \mathrm{s}$, repetition frequency $1 \mathrm{~Hz}$, were applied. CD31 staining in red. Scale bar: 100 $\mu \mathrm{m}$.

Supp Fig. 2. Permeabilization of cells in vivo after EP. Representative images show PI positive nuclei (orange) after EP (Eight square wave electric pulses, amplitude per distance $1300 \mathrm{~V} / \mathrm{cm}$, pulse length $100 \mu \mathrm{s}$, repetition frequency $1 \mathrm{~Hz}$ ). PI and $70 \mathrm{kDa} F D$ (green) were injected i.v. 3 min before the first image. Visible permeabilized nuclei of EC in $3 D$ volume (top insert) and on single z slice (bottom insert, red arrows). Scale bars in the overview image are $70 \mu \mathrm{m}, 30 \mu \mathrm{m}$ in the top right insert and 20 $\mu \mathrm{m}$ in the single $z$ slice insert.

Supp Fig. 3. Quantification ofintravascular $70 \mathrm{kDa}$ FD levels. Relative variation of mean fluorescence intensity as a function of time for $70 \mathrm{kDa} F D$ after EP inside blood vessels is shown. Eight square wave electric pulses, amplitude per distance $1300 \mathrm{~V} / \mathrm{cm}$, pulse length $100 \mu \mathrm{s}$, repetition frequency $1 \mathrm{~Hz}$, were applied in EP group. Ctrl - mice where no EP was applied. $70 \mathrm{kDa} F D$ was injected 3 min before the first image. Mean values \pm SEM are shown.

Supp Fig. 4. Changes in CD31 labelled cell-to-cell junctions volume after EP. The volume of CD31 labelled cell-to-cell junctions was plotted against time. Eight square wave electric pulses, amplitude per distance 1300 $V / c m$, pulse length $100 \mu$ s, repetition frequency $1 \mathrm{~Hz}$, were applied in EP groups. Control - mice where no EP was applied $(n=12)$. EP_return - mice where EP was applied and return of junctions was observed $(n=8)$, EP_no return - mice where EP was applied and no return of junctions was observed $(n=7)$. Error bars indicate SEM. $* P<0.05$ in comparison to control.

Supp Fig. 5. Initial diameter of venule and artery in the imaged $3 D$ volume before EP. No statistically significant difference was observed for either of the blood vessels types. Control - mice where no EP was applied (n=15). EP_return - mice where EP was applied and return of junctions was observed $(n=8), E P \_n o$ return - mice where EP was applied and no return of junctions was observed ( $n=7)$. Mean values are shown and error bars indicate SEM.

Supp Fig. 6. Number of determined CD31 positive voxels before EP. CD31 positive voxels representing the determined $3 D$ volume of labelled cell-to-cell junctions is shown. EP_return-mice where EP was applied and return of junctions was observed $(n=8), E P \_n o$ return - mice where EP was applied and no return of junctions was observed $(n=7)$. Mean values are shown and error bars indicate SEM.

Supp Fig. 7. Platelet aggregation on blood vessels walls after EP. Images offluorescently labelled platelets and $70 \mathrm{kDa} F \mathrm{D}$ before and after EP (top panel) and measurement of $70 \mathrm{kDa} F D$ leakage (bottompanel) in areas associated to platelet aggregation (full circles, top panel) or not associated (empty circles, top panel). Eight square wave electric pulses, amplitude per distance $1300 \mathrm{~V} / \mathrm{cm}$, pulse length $100 \mu \mathrm{s}$, repetition frequency $1 \mathrm{~Hz}$, were applied in EP groups. Scale bar is $100 \mu \mathrm{m}$. 


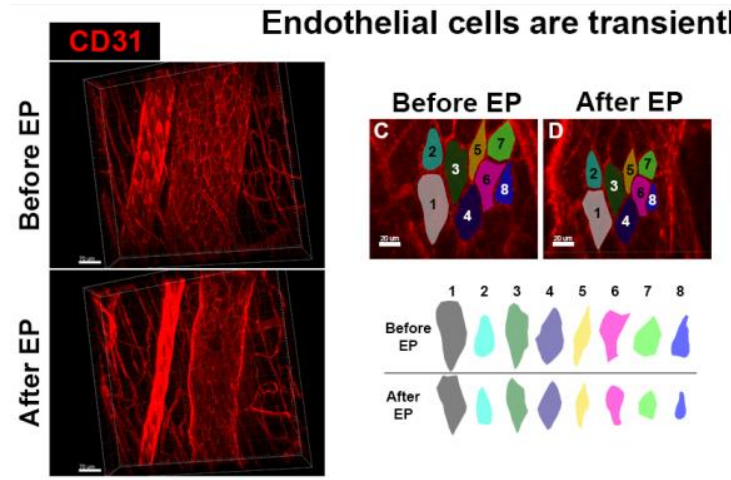

Vascular lock modifies endothelial cell shape

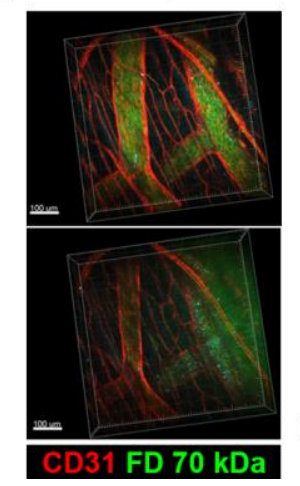

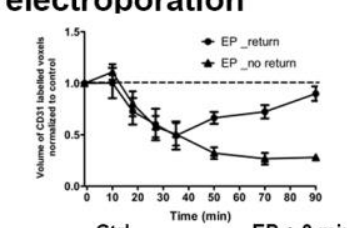

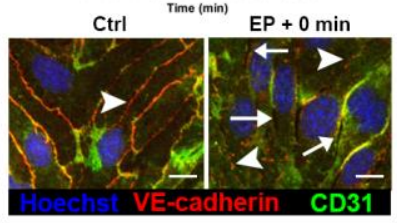

Permeabilization is due to cell-to-cell junction alterations

Graphical abstract 